\title{
Proteomics and metabolomics in cow fertility: a systematic review
}

\author{
Nicolas Aranciaga ${ }^{1,2,3}$, James D Morton $\mathbb{1}^{2}$, Debra K Berg® ${ }^{3}$ and Jessica L Gathercole ${ }^{1}$ \\ ${ }^{1}$ AgResearch, Ltd., Lincoln Research Centre, Proteins and Metabolites Team, Lincoln, New Zealand, ${ }^{2}$ Department of \\ Wine, Food and Molecular Biosciences, Lincoln University, Lincoln, New Zealand and ${ }^{3}$ AgResearch, Ltd., Ruakura \\ Research Centre, Animal Reproduction Team, Hamilton, New Zealand
}

Correspondence should be addressed to / L Gathercole; Email: jessica.gathercole@agresearch.co.nz

\begin{abstract}
Cow subfertility is a multi-factorial problem in many countries which is only starting to be unravelled. Molecular biology can provide a substantial source of insight into its causes and potential solutions, particularly through large scale, untargeted omics approaches. In this systematic review, we set out to compile, assess and integrate the latest proteomic and metabolomic research on cow reproduction, specifically that on the female reproductive tract and early embryo. We herein report a general improvement in technical standards throughout the temporal span examined; however, significant methodological limitations are also identified. We propose easily actionable avenues for ameliorating these shortcomings and enhancing the reach of this field. Text mining and pathway analysis corroborate the relevance of proteins and metabolites related to the triad oxidative stress-inflammation-disease on reproductive function. We envisage a breakthrough in cattle reproductive molecular research within the next few years as in vivo sample techniques are improved, omics analysis equipment becomes more affordable and widespread, and software tools for single- and multi-omics data processing are further developed. Additional investigation of the impact of local oxidative stress and inflammation on fertility, both at the local and systemic levels, is key towards realising the full potential of this field.

Reproduction (2020) $160639-659$
\end{abstract}

\section{Introduction}

\section{Dairy cow subfertility}

Dairy cow reproductive performance has been declining in many countries around the world, whose aetiology seems to be related to changes in cow genetic selection, physiology and management associated with increased milk production (LeBlanc 2010).

Substantial economic losses, management difficulties and animal welfare concerns (Lucy 2001) have motivated a great deal of research to unravel the mechanisms of reduced fertility. Considerable progress to halt the decline in dairy cow fertility has been made in recent years using genetics approaches (Berglund 2008).

To understand the factors underlying this and other physiological conundrums, the trend in clinical and veterinary biochemistry has shifted in the last 30 years from investigating a few molecules in classical studies towards high-throughput methods (commonly referred to as 'omics') analysing hundreds or thousands of compounds.

Improvements in both equipment and data processing have increased the popularity and volume of proteomics and metabolomic studies. They are closer to phenotype than genomic traits and tend to better inform the organism's functional state, while also reflecting genetic factors (Nagana Gowda \& Raftery 2017). Moreover, post-translational regulation processes hinder quantitative predictions of protein levels based on transcript abundance, and therefore proteomics offers unique advantages over transcriptomics (Arnold \& Frohlich 2011).

The relationship between the composition of blood and reproductive biofluids is complex, with certain blood proteins transferred to the uterine fluid (UF) through the uterine epithelium, but secretions from the endometrium being crucial for pregnancy success (Gray et al. 2002). Faulkner et al. (2012) showed that many proteins are differentially abundant in bovine UF compared to plasma. The relevance of integrating molecular research from different reproductive organs is further illustrated by Hunter et al. (2011) description of the mechanisms by which follicular fluid (FF) contributes to the composition of oviduct fluid (OF), as well as the exchange of fluids between OF and UF at the utero-tubal junction. Peritoneal fluid also seems to facilitate interactions among different parts of the reproductive tract (Hunter et al. 2007).

Systemic determinants of bovine fertility have been extensively discussed by Garnsworthy et al. (2008) with a focus on the interaction between feeding, lactation status, metabolic balance and hormones, and are not discussed in this review. 


\section{Aims of this study}

Reproductive success depends on three main elements, namely paternal (comprehensively reviewed by Ceciliani et al. 2017), maternal, and the embryo itself (Artus et al. 2020).

Although the maternal environment is the focus of this work, molecular research into the developing embryo is also featured. The relevance of this distinction between maternal and embryo factors is illustrated by studies trying to assess their relative effects. A previous metaanalysis of 46 sets of data comprising 4560 recipient cows using embryo transfer only, as well as animals inseminated and concurrently receiving embryo transfer, demonstrated clear independent effects of embryos and recipient cows on embryo survival to parturition (McMillan et al. 1998).

Insight from transcriptomics studies, in this area, has been reviewed by Forde and Lonergan (2012) and Ulbrich et al. (2013). Thus, this work is aimed at proteomics and metabolomics with only occasional comparisons to transcriptomics data.

To the best of our knowledge, a comprehensive systematic review that consolidates research in this field is lacking in cows. This systematic review thus has two main aims: to identify the main trends and gaps in research of the bovine female reproductive tract, and to suggest strategies to boost the impact and reach of this field.

\section{Results and discussion}

\section{Search and study inclusion}

This study was designed following PRISMA guidelines for systematic reviews and meta-analyses (Moher et al. 2009). The selection criteria and steps undertaken are depicted in Fig. 1 and described in detail in Supplementary Section 1 (see section on supplementary materials given at the end of this article). The initial search resulted in 1730 potentially suitable articles. Analysis of the titles led to the removal of 1567 papers, including repeated hits, studies targeting male reproduction and articles on topics out of scope. A second stage of selection was based on the information in the abstract, which resulted in a further 54 studies being excluded for one of three reasons: they either presented no original results (i.e. reviews), did not investigate reproductive organs or tissues, or contained overlapping information with an included paper (data reports or abstracts from proceedings). Out of the 109 articles left, 20 studies were excluded that were either purely genomics or transcriptomics, or reported less than six proteins or metabolites. Based on the pilot trial, articles investigating exclusively embryo culture media or late pregnancy and birth complications were only marginally related to the rest of the selected studies. Discrepancies between in vivo and in vitro results using

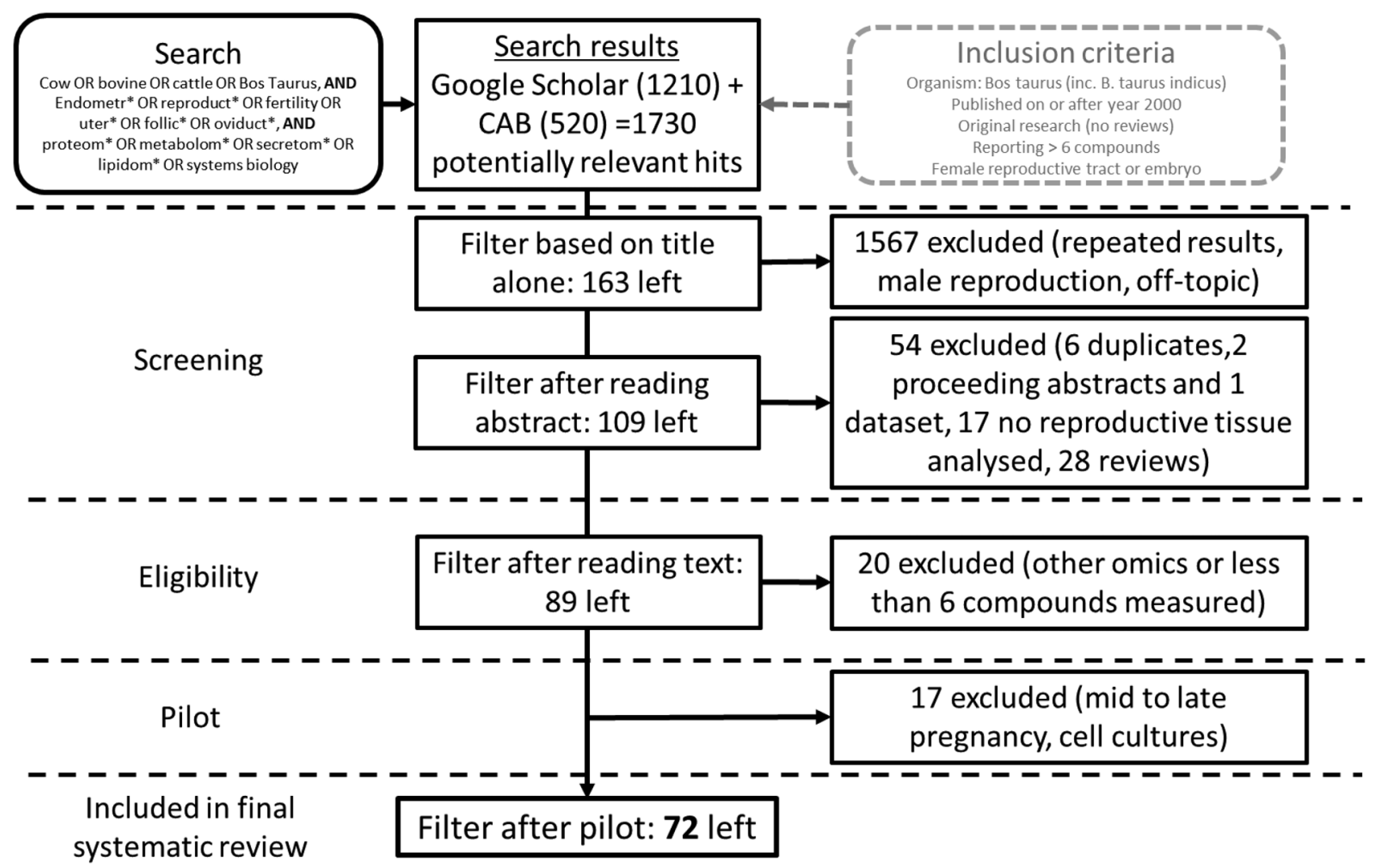

Figure 1 Search strategy and parameters according to the PRISMA guidelines. 
cell cultures were also noted and therefore an additional 17 studies were excluded for a final number of 72 .

Table 1 is adapted from the master table upon which descriptive statistics were based. It presents an overview of the whole set, intended for the reader to locate relevant information at a glance. Supplementary Table 1 contains more detailed descriptions of each study included, classified according to the tissue or organ target: (1) endometrium, (2) embryo, (3) FF and oocytes, and (4) uterine and oviduct fluid (UF and OF, respectively).

Thirty-seven studies $(52 \%)$ reported proteomic results, whereas 34 articles presented metabolomics data $(47 \%)$, and 1 reported both (1\%). Of the papers reviewed, 15 described transcriptomics results in addition to either proteomics or metabolomics, which provided more comprehensive and sounder biological insight in the phenomena investigated. A wide range was observed in the number of compounds measured (quartiles: 18, 53, 653).

\section{Technical considerations}

Studies in cattle tend to have a smaller sample size than humans or mice, due to both logistic and economic reasons (cost of maintenance and space required for large animals). The average sample size in this analysis was reasonably large at 28, although more replicates would increase statistical power and reliability of the trends reported.

As an overarching trend of this review, at first sight, many studies lend themselves to direct comparisons or integration. However, many confounding factors complicate this prospect. These include genetic makeup (milk production and health traits), diverse measurements of reproductive performance, climate, management conditions, including using animals in working farms (which may restrain or affect the design and execution of the experiments (Oenema et al. 2001)), as well as variation in sampling methods.

\section{Breed and genetic makeup}

Perhaps because of the assumed genetic homogeneity among the main cow breeds, this factor often goes unmentioned in articles. However, physiological differences between predominantly beef (Simmental, Angus, Charolais, Limousine) and dairy (Holstein or Holstein-Friesian) cattle (Hayes et al. 2009) or between those and zebu-type breeds (Carvalho et al. 2008) make it imperative to provide this information when presenting results, omics or otherwise. Even cows classed under the same breed name (Holstein) kept together under identical husbandry conditions were shown to differ significantly in milk production, health and reproductive traits (Horan et al. 2004). Gegenfurtner et al. (2019a,b) provided evidence of clear differences in the proteomic composition of UF and OF between cows of different breeds (Holstein vs Montbéliarde) and between Holstein cows with divergent genetic merit for fertility.

Twenty-five articles investigated temperate climate beef cows of European origin, either pure or crossbred. Dairy cows were studied in 19 papers. Zebu/Nellore/ Brahman (Bos taurus indicus) were researched in six studies. The remaining 23 studies did not provide any detail on the breed or type of cow used. Most of these latter studies sourced the animals from abattoirs.

\section{Physiological conditions and management}

Except for the few studies using either cow with endometritis or cystic follicles, all other articles investigated animals without clinical signs of disease. Further to those, a significant part of the studies relied on samples obtained from abattoirs, either for oocytes to generate embryos or as a source of samples, which usually means that little or no information is known about the animals (age, health, management conditions).

Management factors such as housing and feeding regime, time of the day and physiological well-being or stress are confounding factors that may well prevent detecting true differences in the parameters of interest (Nagana Gowda \& Raftery 2017).

Related to the above, agreeing on a standard animal to allow comparisons when investigating the effects of diseases is imperative, especially considering that environmental and husbandry conditions vary widely at country, farm and herd levels (Philipsson et al. 2011).

Currently, there is no simple definition of a healthy animal and the normal concentration range of metabolites or proteins. Subclinical conditions may be ubiquitous and effectively impossible to diagnose using the current standard techniques (Ametaj 2017) and the distinction between clinical and subclinical conditions depends heavily on the choice of testing method (Helfrich et al. 2020). Therefore, we propose that results reported for either clinical or subclinical states deserve consideration, especially under the premise that both processes substantially affect fertility (McDougall 2001, McDougall et al. 2011).

In summary, establishing a healthy standard for comparisons is daunting, but its usefulness, as demonstrated in clinical chemistry (Goldansaz et al. 2017) showcases its relevance. This is further discussed in Section 2.2.4.

\section{Sampling or chemical processing}

The review by Velazquez et al. (2010) comments on advantages and disadvantages of the most typical techniques for sampling of OF and UF (flushing, aspirating and cannulation). The same work recommends in vivo sampling instead of postmortem and stresses the necessity to inhibit proteases or quench metabolism by snap freezing to minimise changes post-sampling (Velazquez et al. 2010). 
Table 1 Studies included, sorted by tissue investigated.

\begin{tabular}{|c|c|c|c|c|}
\hline References & Collection day & Sample & Omics & Keywords \\
\hline \multicolumn{5}{|l|}{ Embryo } \\
\hline Banliat et al. 2019b & 7 & Embryo (in vitro) & M & Effect of hormone treatments \\
\hline Demant et al. 2015 & 5,7 & Embryo (in vitro) & $\mathrm{P}$ & Proteome changes in early development \\
\hline Deutsch et al. 2014 & $1,1.5,2$ & 1,2 and 4 -cell (in vitro) & $\mathrm{P}$ & Development; oocytes as reference \\
\hline Goncalves et al. 2016 & $0,2,3,7$ & $\begin{array}{l}\text { Oocytes, embryos (in } \\
\text { vitro) }\end{array}$ & M & MS-imaging to distinguish embryo stages \\
\hline Hemmings et al. 2012 & $7,8,9$ & $\begin{array}{l}\text { Oocytes, embryos (in } \\
\text { vitro) }\end{array}$ & M & Modelling oocyte competence \\
\hline Jensen et al. 2014a & 8 & Embryo (in vitro) & $\mathrm{P}$ & Descriptive, two embryonic tissues \\
\hline Jensen et al. $2014 b$ & 13 & Embryo (in vitro) & $P$ & Different stages of embryo development \\
\hline Massicotte et al. 2006 & $0--2.5$ & $2,4,8$-cell (in vitro) & $P$ & Maternal housekeeping proteins \\
\hline Sturmey et al. 2010 & 7 & Embryo (in vitro) & M & Embryo sex-metabolism in vivo vs in vitro \\
\hline \multicolumn{5}{|l|}{ Endometrium } \\
\hline Belaz et al. 2016 & Oestrus: 4,7 & Endometrium, oviduct & M & Lipidome profiling of uterus and oviduct \\
\hline Berendt et al. 2005 & Preg + Oestrus: 18 & Endometrium & $P$ & Monozygotic twins: pregnant vs oestrus \\
\hline Choe et al. 2010 & Oestrus: $0-4$ & Endometrium & $P$ & Endometritis \\
\hline Giergiel et al. 2018 & Oestrus & Endometrium & $\mathrm{P}$ & Heifers vs calves \\
\hline Groebner et al. 2011a & Preg: $12,15,18$ & Endometrium & $M,(T, P)$ & Kynurenine metabolic pathway \\
\hline Zhang et al. 2017 & $21-35 d p p$ & Endometrium (plasma) & $\mathrm{P}$ & Endometritis \\
\hline \multicolumn{5}{|l|}{ Follicular fluid and oocytes } \\
\hline Aller et al. 2013 & Oestrus: 4,13 & FF (plasma) & $M,(P)$ & Small vs large follicles and FF vs plasma \\
\hline Annes et al. 2019 & NA & FF and oocytes & $M,(T)$ & Lipids of oocytes and FF in follicles \\
\hline Bender et al. 2010 & Across oestrus & FF (plasma) & M & FF vs plasma, subordinate vs main follicle \\
\hline Bhojwani et al. 2006 & $0,0.5,1$ & Oocytes (in vitro) & $P$ & Phosphorylation during in vitro maturation \\
\hline Forde et al. 2016a & Oestrus & FF (plasma) & M & Effect of lactation on FF composition \\
\hline Guerreiro et al. 2018 & Dioestrus & $\mathrm{FF}$ & M & $\begin{array}{l}\text { Higher, normal, and lower oocyte } \\
\text { producers }\end{array}$ \\
\hline Leroy et al. 2004a & NA & FF (plasma) & M & Metabolites in FF re follicle size and blood \\
\hline Leroy et al. $2004 b$ & $16,46 d p p$ & FF (plasma) & M & Metabolites in FF re time after calving \\
\hline Leroy et al. 2005 & $16,46 d p p$ & FF and oocytes & M & $\begin{array}{l}\text { Effect of fatty acids on In vitro oocyte } \\
\text { maturation }\end{array}$ \\
\hline Maniwa et al. 2005 & Oestrus & $\mathrm{FF}$ & $\mathrm{P}$ & Cystic vs healthy follicles \\
\hline Matoba et al. 2014 & NA & FF, follicle cells & $M,(T)$ & FF good and bad embryos \\
\hline Memili et al. 2007 & $\mathrm{NA}$ & Oocytes, cumulus cells & $\mathrm{P}$ & Descriptive: germinal vesicle oocytes \\
\hline Moore et al. 2015 & Oestrus: 7 & FF (plasma) & M & Genetic merit for fertility \\
\hline Orsi et al. 2005 & Across oestrus & $\mathrm{FF}, \mathrm{ECM}$ & M & FF vs embryo culture medium \\
\hline Renaville et al. 2010 & Dioestrus & FF (plasma) & M & Active $((\mathrm{E} 2) /(\mathrm{P} 4)>1)$ vs inactive follicles \\
\hline Rodrigues et al. 2019 & NA & $\mathrm{FF}$ & $\mathrm{P},(\mathrm{T})$ & EVs in FF protect embryos from heat stress \\
\hline Zachut et al. 2016 & Pre-ovulatory & $\mathrm{FF}$ & $\mathrm{P}$ & Repeat breeders vs control (normal) \\
\hline \multicolumn{5}{|l|}{ Uterine and oviduct fluid } \\
\hline Alavi-Shoushtari et al. 2006 & Across oestrus & UF (plasma) & $\mathrm{P}$ & Globulins and albumin \\
\hline Almiñana et al. 2017 & Oestrus: $1--5$ & $\mathrm{OF}(\mathrm{EV} \mathrm{s})$ & $\mathrm{P}$ & EVs in OF and in vitro oviduct culture \\
\hline Almiñana et al. 2018 & Across oestrus & $\mathrm{OF}(\mathrm{EV} \mathrm{s})$ & $\mathrm{P},(\mathrm{T})$ & EVs in OF; ncRNA \\
\hline Banliat et al. 2019a & Across oestrus & OF & M & Phospholipids in OF in oestrus (2 horns) \\
\hline Banliat et al. 2020 & $3-5$ & OF, embryo (in vitro) & $\mathrm{P}$ & OF-embryo interacting proteins \\
\hline Beltman et al. 2014 & Preg: 7 & UF & $\mathrm{P}$ & Viable vs degenerate embryo \\
\hline Faulkner et al. 2012 & Oestrus: 7 & UF (plasma) & $\mathrm{P}$ & UF vs blood plasma proteomes \\
\hline Faulkner et al. 2013 & Oestrus: 7,15 & UF & $\mathrm{P}$ & Low vs high P4 effect on UF proteome \\
\hline Forde et al. 2013 & Preg: $13-19$ & UF $(\mathrm{P})$, embryo $(\mathrm{T})$ & $\mathrm{P},(\mathrm{T})$ & Effect of P4 on gene expression \\
\hline Forde et al. $2014 a$ & Preg: 10-19 & UF $(P)$, embryo $(T)$ & $\mathrm{P},(\mathrm{T})$ & Protein changes in pregnancy \\
\hline Forde et al. 2014b & Preg + Oestrus: $10-19$ & UF & $M,(T)$ & $\begin{array}{l}\text { Changes pregnant vs oestrus at different } \\
\text { days }\end{array}$ \\
\hline Forde et al. 2015 & Preg + Oestrus: 16 & UF (P), embryo $(\mathrm{T})$ & $\mathrm{P},(\mathrm{T})$ & Effect of embryo on UF composition \\
\hline Forde et al. $2016 b$ & Preg: 19 & UF $(M)$, embryo $(T)$ & $M,(T)$ & $\begin{array}{l}\text { AA consumption differences by embryo } \\
\text { gender }\end{array}$ \\
\hline Forde et al. 2017 & Preg: 19 & UF (M), embryo (T) & $M,(T)$ & Heifers, lactating and dry cows \\
\hline Gegenfurtner et al. 2019a & Oestrus: 3 & OF & $\mathrm{P}$ & $\begin{array}{l}\text { Metabolic status, breed effects on OF } \\
\text { proteome }\end{array}$ \\
\hline Gegenfurtner et al. 2019b & Pregnancy: 19 & UF & $\mathrm{P}$ & Effect of genetic merit on UF proteome \\
\hline Groebner et al. 2011b & Oestrus: $12,15,18$ & UF & $M,(T)$ & Changes in $41 \mathrm{AA}$ through oestrus \\
\hline Harlow et al. 2018 & Oestrus: 9 & UF & $\mathrm{P}$ & Effect of diet on UF composition \\
\hline Helfrich et al. 2020 & $43-62 d p p$ & UF & $\mathrm{P},(\mathrm{T})$ & Subclinical endometritis effect on UF \\
\hline Hugentobler et al. 2007a & Oestrus: $0-14$ & UF, OF & $\mathrm{M}$ & Changes in $(\mathrm{AA})$ through oestrus \\
\hline
\end{tabular}


Table 1 (Continued).

\begin{tabular}{|c|c|c|c|c|}
\hline References & Collection day & Sample & Omics & Keywords \\
\hline Hugentobler et al. $2007 b$ & Oestrus: $0-14$ & OF, ÚF (plasma) & M & Changes in (ions) through oestrus \\
\hline Hugentobler et al. 2008 & Oestrus: 0-14 & UF (plasma) & M & Glucose, lactate, pyruvate (energy) \\
\hline Hugentobler et al. 2010 & Oestrus: 3,6 & UF, OF & M & Effect of infused P4 on fluid composition \\
\hline Lamy et al. 2016a & Across oestrus & OF & $P$ & Side and oestrus stage effect \\
\hline Lamy et al. 2016b & Across oestrus & OF & M & Steroids changes through oestrus \\
\hline Ledgard et al. 2012 & Oestrus: $5,9,14$ & UF & $P$ & Asynchronic ET effect on proteome \\
\hline Ledgard et al. 2015 & 15 and $42 d p p$ & UF & $\mathrm{P}$ & Subclinical endometritis vs healthy cows \\
\hline Moraes et al. 2020a & Preg+Oestrus: 17 & UF & $M,(T)$ & Effect of preg. on UF lipid composition \\
\hline Moraes et al. 2020b & Preg + Oestrus: 17 & UF & $\mathrm{P}, \mathrm{M},(\mathrm{T})$ & $\begin{array}{l}\text { Effect of preg. on UF proteome, } \\
\text { metabolome }\end{array}$ \\
\hline Mullen et al. 2012 & Oestrus: 7, 13 & UF & $\mathrm{P}$ & High fertility heifers' UF proteome \\
\hline Muñoz et al. 2012 & Preg + Oestrus: 8 & UF & $\mathrm{P}$ & $\begin{array}{l}\text { Differences in UF of in vivo vs Al } \\
\text { pregnancies }\end{array}$ \\
\hline Papp et al. 2019 & Oestrus: 1,3 & OF & $\mathrm{P}$ & Protein binding beads, OF flushing \\
\hline Passaro et al. 2016 & Preg + Oestrus: 7 & UF & $\mathrm{P}$ & Proteome changes induced by pregnancy \\
\hline Pillai et al. 2017 & Across oestrus & OF & $\mathrm{P}$ & Ex vivo vs in vitro oviduct secretions \\
\hline Ribeiro et al. 2016a & Preg+Oestrus: 15 & UF $(M)$ & $M,(T)$ & Non-preg vs several embryo shapes \\
\hline Simintiras et al. 2019a & Oestrus: $12,13,14$ & UF & M & Lipids (P4 suppl. effect) \\
\hline Simintiras et al. $2019 b$ & Oestrus: $12,13,14$ & UF & M & $\begin{array}{l}\text { Nucleotides, vitamins, etc. (P4 suppl. } \\
\text { effect) }\end{array}$ \\
\hline Simintiras et al. $2019 c$ & Oestrus: $12,13,14$ & UF & M & AA, carbohydrates (P4 suppl. effect) \\
\hline Sponchiado et al. 2019 & Preg + Oestrus: 7 & UF & $M,(T)$ & Embryo modulates UF metabolome \\
\hline Tribulo et al. 2019 & Oestrus: $0,3,5,7$ & UF & M & $\begin{array}{l}\text { Changes in UF metabolome in early } \\
\text { oestrus }\end{array}$ \\
\hline
\end{tabular}

AA, Amino acids; Al, artificial insemination; Dpp, days post-partum; E2, oestradiol; ET, embryo transfer; EV, extracellular vesicles; FF, follicular fluid; M, metabolomics; MS, mass spectrometry; OF, oviduct fluid; P, proteomics; P4, progesterone; Preg, pregnant; T, transcriptomics; UF, uterine fluid.

In parentheses, secondary samples or omics technologies

A further consideration was raised by Velazquez et al. (2010) concerning chiefly in vivo UF sampling by flushing: due to differences in size and shape among uteri, the amount of liquid recovered varies substantially. The addition of an internal standard (a non-naturally occurring molecule such as an isotope-labelled amino acid) to the flushing medium may provide a means to correct for such differences, as reported by Vilella et al. (2013) in a human trial. However, this strategy has not been reported in any of the studies reviewed herein.

Two recent developments for reproductive fluid sampling deserve mention due to their increased precision. Papp et al. (2019) used transvaginal endoscopy to gain access to the oviduct of live animals, and sampled proteins by two methods. One was flushing using a catheter with multiple holes using, to the authors' knowledge, the only technique that allows flushing oviducts in vivo (Besenfelder et al. 2001). The other method consisted on the introduction of magnetic silica-C4 beads that bind proteins by hydrophobic adsorption. Comparisons of the two sampling methods show that both were equally robust, and that flushing resulted in one order of magnitude higher amount of protein recovered, but more proteins were identified by the $\mathrm{C} 4$ bead method.

There was a $45 \%$ overlap in proteins detected by both methods (Papp et al. 2019). Taking into consideration that beads with different binding properties could be employed to customise the proteomic fraction targeted, the authors concluded that several approaches may be used in a complementary fashion for deeper coverage (Papp et al. 2019).

Helfrich et al. (2020) sampled UF using a device comprising a flexible Merocel $(2 \mathrm{~mm} \times 4 \mathrm{~mm} \times 102.5$ $\mathrm{mm}$ ) sponge adhered to a plastic cannula. This was inside a working channel (stainless steel tube) with a blunt obturator to reach the uterus avoiding contamination from vagina and cervix. The sponge was rotated inside the uterine lumen for $2 \mathrm{~min}$, and after retraction, proteins were extracted with PBS buffer. The constant weight of the sponge and tube and use of consistent volume of buffer allowed calculating a precise dilution factor and therefore mass of protein. This sampling technique combines low invasiveness with a reasonable sampling area (much more than by aspiration), while avoiding imprecisions due to dilution typical of flushing procedures.

The literature on the impact of sampling on pregnancy is equivocal. Berkkanoglu et al. (2006) reported no detrimental effect of uterine flushing immediately prior to embryo transfer in human. Martins et al. (2018), however, showed that bovine uteri needed 4 days to recover from the flushing disruption to return to normal pregnancy rates.

Blood contamination Furthermore, an often overlooked but highly detrimental phenomenon is the occurrence of blood contamination during sampling. This happens often (but not exclusively) during the introduc- 
tion of a catheter through the vulva to collect UF or OF. Nonetheless, conspicuously few of the studies surveyed addressed or even mentioned this issue. Considering that many of the proteins UF are also found in plasma (Faulkner et al. 2012), determining whether relative changes are indeed the consequence of a physiological process instead of an artefact due to blood contamination may change completely the results of a trial. Although to a lesser extent, endometrial tissue is also liable to the same issue (Berendt et al. 2005). In this regard, Zhang et al. (2017) found proteins of the blood complement system in endometrial samples which they attributed to plasma contamination, possibly as a result of haemorrhage.

In some studies, a simple measure taken was to exclude samples presenting a red tinge (Martins et al. 2018). While this is certainly a step in the right direction, it is known that even visually transparent samples can still be contaminated (Guise \& Gwazdauskas 1987). The approach taken by Helfrich et al. (2020) to quantify the degree of blood contamination by photometry is noteworthy. Measuring absorbance at $570 \mathrm{~nm}$ (haemoglobin peak) of blood and UF, they created a standard curve and thus estimated percentage of blood on UF samples. This strategy appears to assume haemoglobin occurs naturally in minute amounts in UF, although this is at odds with Faulkner et al. (2012), who reported haemoglobin to be more abundant in UF than blood.

A large proportion of typically intracellular proteins are found in FF (Maniwa et al. 2005), OF (Lamy et al. 2016a) and UF (Forde et al. 2014a). This is likely caused by a combination of (1) epithelial cell renewal and apoptosis (Mondejar et al. 2012), (2) damage during sampling (Papp et al. 2019), and (3) some of those proteins being secreted by alternative, potentially undescribed mechanisms (Gegenfurtner et al. 2019a). The reports of Almiñana et al. (2017) on the role of exosomes (small membrane-bound vesicles of endocytic origin) in oviduct-embryo communication showcasing their relevance in luminal fluids points in that direction. Supporting this are the reports of Passaro et al. (2016) and Harlow et al. (2018) that over half of the proteins detected in UF were categorised as exosomal (Gene Ontology), Banliat et al. (2020) also found 33 embryointeracting proteins previously detected in oviductal exosomes along with 20 proteins secreted by nonclassical pathways, and Rodrigues et al. (2019) reported embryo-protective effects of whole FF and FF exosomes against heat stress.

All in all, the multifaceted interface of glandular secretions, blood transudates, cellular debris and exosomes in these biofluids in physiological conditions add complexity to the task of accounting for contamination due to sampling only.

The relevance of integrating molecular research from different reproductive organs is demonstrated by physiological research. Hunter et al. (2011) describe mechanisms by which FF contributes to the composition of OF, as well as the exchange of fluids between OF and UF at the utero-tubal junction. Peritoneal fluid also seems to facilitate interactions among different parts of the reproductive tract (Hunter et al. 2007).

\section{Analytical platform and informatic analysis}

Metabolomic studies face several hindrances, among which is the challenge in untargeted studies of interpreting mass spectrometry data and mapping it to known compounds (Patti et al. 2012), and in quantitative comparisons between studies, shared with other omics (reviewed by Ceciliani et al. 2018).

Even for compounds that are assigned a potential identity, a big hurdle is distinguishing between isomers (molecules with the same atomic composition but a different conformation), which share many physicochemical properties and are therefore challenging to separate by chromatographic and spectrometric methods (Destaillats \& Cruz-Hernandez 2007). Although these isomers are physically similar, they often have different biological roles (Hullin-Matsuda et al. 2009). Integrating ion mobility spectrometry (IMS) to the typical liquid chromatography-mass spectrometry setups has been shown to help in distinguishing fatty acids with different orientation or position of double bonds (Kyle et al. 2016) although this technique has not been utilised to investigate lipids in cow fertility studies.

Several articles surveyed reported absolute concentrations of metabolites. The work by Sponchiado et al. (2019) is unique in that they reported metabolite concentration values normalised to the respective endometrial area, in an example of absolute quantitation with an omics approach. This results from sampling and analysing UF from limited portions of the endometrium, which was performed postmortem. On a related note, a system for absolute quantification of proteins is also being developed, using a mass spectrometry function called selected reaction monitoring (SRM), combined with synthetic peptide standards of the target peptides. This targeted method allows quantification at the attomole concentration range at the cell level (Deutsch et al. 2019) and may represent a new standard for proteomics experiments.

Standardising measurements across studies, as seen previously, is fundamental to take full advantage of any potential biomarkers discovered. To this effect, the Livestock Metabolome Database (LMDB, http://www. Imdb.ca, Goldansaz et al. 2017) takes care precisely of this need by offering an open-access database comprising all metabolites reported from many tissues and biofluids of the five major domestic mammals (cow, sheep, goat, horse and pig). Perhaps due to the incipient state of this resource, the only component of the reproductive tract represented is FF, which is otherwise an excellent addition to omics veterinary. 
Integration Most of the recent articles surveyed have presented one or more kinds of molecular integration analysis, aiding in the navigation of the myriad compounds discussed. A typical approach for gene and protein data is Gene Ontology (GO) term enrichment analysis, which delivers insight on important molecular functions, cellular components and biological processes most closely linked to the phenomenon of interest (Ashburner et al. 2000, The Gene Ontology Consortium 2019).

Further types of informatic inquiry are pathway and network analysis. Pathway analysis allows integration of metabolomics as well as of multi-omics data and represents a powerful tool to uncover biological processes unapparent in single omics enquiries (Li et al. 2013).

On that topic, to the authors' knowledge, only one study has attempted both proteomics and metabolomics analysis in a single trial in cattle. Moraes et al. $(2020 a, b)$ performed an exhaustive multi-omics exploration, which included secretomics (i.e. proteomics and metabolomics) of UF, coupled with transcriptomics of endometrium and conceptus. The use of pathway analysis tools supported this, but much of the integration still required a sizable amount of manual input. As multiomics research becomes more widespread, software applications are expected to provide means of assisting with this daunting task (Pinu et al. 2019).

\section{Reporting}

When extracting data for this study, it was evident that the requirements for publication have become more stringent over the years; for instance, while only a few of the early studies have included raw data or the full list of compounds identified, almost all articles from 2010 onwards present either or both as supplemental information. This trend towards more transparent, reproducible research is observed in many scientific fields. The ARRIVE (Animals in Research: Reporting In vivo Experiments) guidelines (Kilkenny et al. 2010) and the REFLECT (Reporting Guidelines for Randomized Controlled Trials for Livestock and Food Safety) statement (O'Connor et al. 2010) have provided an excellent starting point for studies requiring experimentation on animals.

Despite said improvements, reporting of many aspects from both guidelines was incomplete or nonexistent in many studies, including recent ones. This has serious implications for both comparing results across studies as well as for repeatability of the experiments described.

Despite the considerable advance apparent over the years, Winder et al. (2019) reached similar conclusions to ours when examining completeness of reporting in a subset of animal studies (chiefly bovine) published in a high-ranking publication for its field (Journal of Dairy
Science) in 2017, which shows that there is still a big margin for improvement.

\section{Key molecules and processes}

We performed a comparative analysis by two complementary methods. The first one was an appraisal relying on the authors' background knowledge and understanding of biochemistry and physiology. Subsequently, we augmented the reach of the first selection by text mining combined with biological database exploration, that is, pathway and network analyses (Supplementary Section 1.3).

Most articles included centre their discussion on metabolic processes. While a great deal of insight has been gained, as a result, here we examine processes that might be equally impactful on fertility but have been somewhat overlooked.

Articles studying physiological models were at first analysed separately from those focusing on endometritis (Ssection 2.4.4). Key molecular results were subsequently contrasted between the two classes. Figure 2 includes the molecules discussed in this section in the temporal context of early embryo development.

The most frequently mentioned metabolite groups were amino acids, carbohydrates and certain lipid classes (especially fatty acids and phospholipids). Metabolites, however, typically participate in multiple processes, which complicates generalisations regarding their specific influence on reproduction.

Conversely, the list of top proteins provided more readily understandable insight. Ranked by frequency, some of the most common proteins and protein classes related to inflammation, immune response and oxidative stress were annexins, serpins, heat shock proteins, S-100 proteins (these last two belonging to the 'acute response proteins' group), glutathione-S-transferases and tissue inhibitor of matrix metalloproteinase 2 (TIMP2). The specific proteins surveyed are discussed subsequently. The fundamental influence of those processes (both systemic and local) on reproduction appears to be somewhat disregarded in untargeted molecular research as well as in most of the articles reviewed that used healthy animals and is illustrated by the high number of molecules reported that participate in said processes.

One noteworthy exception is the work of Groebner et al. (2011b), which specifically addressed the molecular mechanisms of the interplay between immunity and reproduction. An important finding is that many cytokines (especially interleukin 10) are upregulated in cyclic endometrium at day 18 of oestrous cycle (Groebner et al. 2011b). Groebner et al. (2011b) also reported evidence of significant upregulation of the kynurenine pathway between days 12 and 18 of 


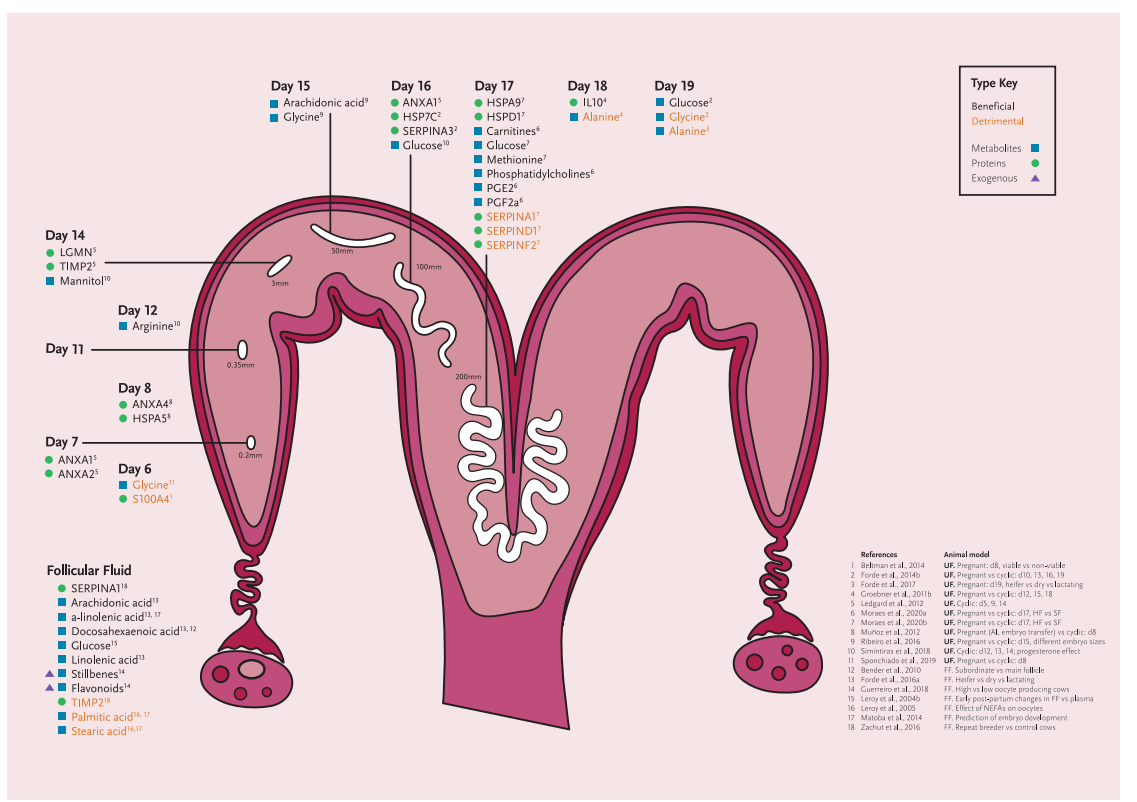

Figure 2 Potential biomarkers of uterine suitability for pregnancy related to inflammation and oxidative stress in the cow's reproductive tract, across early pregnancy and oestrus. 'Exogenous' refers to compounds not originating from diet or the environment. Al, artificially inseminated; $d$, day; $F F$, follicular fluid; HF, highly fertile; NEFAs, non-esterified fatty acids; SF, subfertile; UF, uterine fluid. For protein and metabolite names, refer to text. pregnancy, stimulated by interferon-tau. Both increased abundance of interleukin 10 and activation of the kynurenine pathway may be required to prevent maternal rejection of the conceptus (Shirasuna et al. 2012). This evidence points to an active control of inflammation and autoimmunity by the endometrium.

Gilbert (2019) reviewed the effect of disease on fertility and presented a causal chain of disease, causing inflammation and increased oxidative stress, leading to decreased fertility, although the interaction of these elements is more complex than this linear model.

Complementing the aforementioned review is the work of Guerin et al. (2001) which sheds light on the influence of oxidative stress on reproduction. They discuss how endogenous (especially purine metabolism and oxidative phosphorylation) and exogenous (oxygen, excess of glucose, some metallic ions, xenobiotics) factors generate reactive oxygen species (ROS) that create an inhospitable environment for oocyte and embryo development. A variety of embryo-protective mechanisms to both prevent the generation of ROS and to neutralise them have been found in cattle, human and mouse; these include internal (i.e. cellular, in the oocyte or embryo itself) and external (extracellular fluids, e.g. FF and OF). Likewise, they can be classed as enzymatic (e.g. glutathione reductase) and non-enzymatic (antioxidant molecules such as vitamins, some peptides and amino acids, etc.).

One of the less intuitive aspects of diseases (both systemic and local) is possibly the extension of their effects on reproduction well after disease resolution (Gilbert 2019). This influence does not only occur in the uterine environment, but also at the level of ovary and oocyte production (Gilbert 2019). In fact, bacterial lipopolysaccharide or endotoxin (a harmful compound produced by many microorganisms) due to infection can be found in FF in higher concentrations than in systemic circulation or even in the infected uterus (Groebner et al. 2011a, Gilbert 2019).

\section{Proteins}

This section lists the most frequently mentioned proteins and protein families surveyed along with a summary of their biological significance as gathered from the relevant studies.

Annexins Annexins are a family of calcium-dependent multifunctional proteins involved, among other processes, in regulation of arachidonic acid metabolism and inhibiting activity of pro-inflammatory enzymes (Hutchinson et al. 2011). Ledgard et al. (2012) and Faulkner et al. (2013) found increased abundance in UF of those proteins on day 9 of oestrus compared to day 5 , and day 7 of pregnancy compared to day 15 of pregnancy, respectively. Faulkner et al. (2013) suggest that this might be related to inhibition of phospholipase P2, an enzyme in the prostaglandin synthesis pathway (of pro-inflammatory and pro-luteolytic result). This exemplifies the temporal regulation of inflammation in early pregnancy.

Other annexins have been reported, albeit less frequently than Annexins A1 and A2. Annexin A4, for instance, was found to be upregulated in UF at day 8 pregnant compared to cyclic cows (Muñoz et al. 2012) and is suggested to play a similar anti-inflammatory role as Annexins A1 and A2.

Serine protease inhibitors (SERPINs) Several members of this diverse family of protease inhibitors have roles 
related to inflammation and infection, and are proposed to constitute a mechanism of immunomodulation dependent on hormonal signals (Simintiras et al. 2019a). Some of these are potential biomarkers of different degrees of endometritis and are discussed in Section 2.4.4.

SERPINA1 was downregulated in FF of repeat breeder cows; this was hypothesised to underlie the accelerated follicular growth typically associated with lower fertility (Zachut et al. 2016).

In UF, SERPINA1 along with SERPINF2 and SERPIND1 were more abundant on day 17 of pregnancy in sub-fertile compared to highly fertile beef heifers, all associated to haemostasis (blood coagulation) pathways and without any reported links to fertility (Moraes et al. 2020a). SERPINA3 was reported as 1 of the top 20 most abundant proteins in UF of day 16 pregnant cows (Forde et al. 2014a) but was not detected at day 16 of oestrus in cyclic cows, although no differences were found in its transcript abundance (Forde et al. 2015). Many SERPINs (A3-1, A3-7, A3-8, D1 and H1) were detected in OF (Pillai et al. 2017, Gegenfurtner et al. 2019b), potentially involved in zona pellucida-sperm interactions (Cesari et al. 2010). The structural diversity of SERPINs entails equally varied physiological functions, both beneficial and detrimental to reproduction.

Acute response proteins: S100 and HSP (heat shock proteins) Acute response proteins are part of the early immune response, upregulated to respond to stimuli, such as infection and inflammation. Many of these have been detected in bovine UF and OF, several of which are more abundant in post-ovulation compared to preovulation in OF (Lamy et al. 2016a).

Heat shock proteins (HSP) were first described in relation to their defensive role against heat stress but were subsequently found to be involved in protection from an array of stress factors (De Maio 1999). There is consistent reporting of upregulation of HSPs caused by pregnancy in several parts of the reproductive tract. HSPA5 was found to be more abundant in UF at day 8 of pregnancy compared to day 8 of oestrus (Muñoz et al. 2012) and suggested to protect the embryo from proteolytic damage (Lamy et al. 2016a). HSP90, HSPA6 and HSPA8 were found in higher abundance in OF in post-ovulatory compared to pre-ovulatory phase but their role is not clear (Forde et al. 2015); in the same work, HSP90 was more abundant at post-ovulatory phase in ipsilateral OF compared to other stages and side, and is proposed to stimulate prostaglandin $E_{2}$ secretion to regulate embryo transport.

Pregnant heifers UF contained HSPA9 (involved in embryonic attachment (Bhagwat et al. 2014)) and HSPD1 (annotated as a mitochondrial protein) concentrations ten-fold higher compared to cyclic heifers (Moraes et al. 2020a). Another protein, HSP10 was shown to be produced by both the embryo and the endometrium (Forde et al. 2015).

Several studies reported HSP70 (a family comprising several proteins of molecular weight around $70 \mathrm{kDa}$, including HSPA1-14) as relevant to fertility or related conditions; due to methodological limitations, the precise protein was not always specified. Maniwa et al. (2005) found HSP70 to be more abundant in FF of cystic follicles, potentially decreasing the normal rates of apoptosis observed in healthy follicles. These proteins are also important in protection against oxidative stress and inflammation in UF of pregnant animals (Muñoz et al. 2012). Members of the HSP70 family were also detected by Massicotte et al. (2006) as constitutively expressed in oocytes; the authors suggested a role as a protein carrier.

Worthy of note is that in a study of exosomes and extracellular vesicles in bovine OF, numerous microRNAs potentially inhibiting HSP genes were reported by Almiñana et al. (2018) as varying across oestrus stages. Regulation of these proteins at different levels is likely relevant to embryo development.

S100 proteins are a family of proteins that bind calcium and tend to be overexpressed in disease, mediating inflammation and with antimicrobial activity (Lukanidin \& Sleeman 2012). S100A8 and S100A9 were found to be higher in cyclic day 7 UF compared to day 13 and may modulate maternal immune function; S100A4 exhibited the opposite trend (Mullen et al. 2012). S100A4, in turn, was suggested to be detrimental to embryo development at day 7 of pregnancy by an altered balance between pro- and anti-inflammatory processes (Beltman et al. 2014). Talbot et al. (2010) also found S100A4 to be among the most abundant proteins in trophectoderm in vitro cell culture.

Considering the relatively high abundance and the effect on reproduction of acute response proteins, they deserve increased attention in future molecular research.

Glutathione-S-transferases This protein family is also involved in response to oxidative stress, fulfilling a protective role in the uterus via the detoxification of ROS (Faulkner et al. 2013). Two glutathione-S-transferases (GSTM1 and GSTM2) were upregulated in UF on day 7 of oestrus compared to in day 15 (Faulkner et al. 2013). Ledgard et al. (2012) found that GSTM1 abundance was higher in UF in day 9 vs day 5 of oestrus. This demonstrates that reduction of oxidative stress may play a crucial part in embryo development and suggests regulation by progesterone.

Tissue inhibitor of matrix metalloproteinase 2 (TIMP2) This protein is suggested to act in limiting trophoblast invasion and possibly in endometrial remodelling (Faulkner et al. 2013). UF from mature cows generated by somatic cell nuclear transfer had lower TIMP2 relative abundance compared to heifers on day 
14 of oestrus, but interestingly it was not detected on day 5 or 9 of oestrus in animals of either parity, and thus is hypothesised to be dependent on progesterone regulation (Ledgard et al. 2012). Corroborating the temporal regulation of this protein, Forde et al. (2014b) reported a TIMP2 increase in pregnant UF at day 16 compared to days 10 and 13 correlating with IFNT changes, and Faulkner et al. (2013) an increase of TIMP2 in UF at day 15 vs day 7 of oestrus. TIMP2 is considered important for successful embryo elongation (Ulbrich et al. 2011) as well as for regulation of protease activity during implantation (Ledgard et al. 2009).

In other sections of the reproductive tract TIMP2 may have detrimental effects for fertility. Zachut et al. (2016) found that TIMP2 was twice as abundant in FF of repeat breeder (low fertility) cows compared to control cows. They theorise that both too low or too high concentrations of this protein impede the formation of complexes with other proteins, and in this way, it is correlated to alterations in ovulation.

All in all, many proteins related to fertility differences are involved in immune, inflammatory and oxidative processes. This was understated in most of the literature surveyed. More molecular research specifically on the immune milieu of the reproductive tract is needed, in agreement with the recommendations of Ott (2019).

\section{Metabolites}

Many of the surveyed metabolomic studies used targeted approaches that look at a particular set of metabolites. This, in turn, is reflected on the frequency of metabolite classes discussed here. Even in non-targeted analyses, amino acids (AA) were also shown to be the most abundant metabolite class in UF (Tribulo et al. 2019).

Amino acids The amino acids most often reported as significant in the biological processes investigated were arginine, glycine, alanine and methionine.

Arginine is an amino acid with many functions related to fertility, which include being essential to produce interferon tau (IFNT) and even being an embryonic growth factor by itself, by mechanisms not fully characterised (Wang et al. 2015). However, Forde et al. (2017) found arginine in lower concentration in UF of dairy heifers compared to both lactating and dry multiparous cows, all at day 17 of pregnancy, potentially implying that high levels of arginine in UF might be detrimental to pregnancy.

Glycine and alanine have been reported as the most abundant amino acids in OF (Lamy et al. 2016b) and in UF (along with glutamic acid) at days 7 and 19 of pregnancy (Forde et al. 2017). In contrast, Tribulo et al. (2019) reported the most abundant AA in the first 7 days of the oestrus cycle being tryptophan, phenylalanine, tyrosine and leucine.
Glycine and alanine are both small, non-polar amino acids, which are transported by the same carrier proteins (Forde et al. 2014b). Glycine has been hypothesised to protect the embryo against osmotic stress and can be used by the embryo as an energy source in OF (Lamy et al. 2016b), and can be converted to alanine. There is conflicting evidence about the relationship between glycine concentration in UF with reproductive success: Forde et al. (2014b) found no effect of pregnancy on UF glycine concentrations in beef heifers from day 10 to 19 after ovulation. In contrast, Forde et al. (2017) reported lower abundance of both glycine and alanine in dairy heifers' UF compared to both lactating and dry mature dairy cows (all at day 19 of pregnancy), while Sponchiado et al. (2019) found reduced glycine concentration in UF at day 7 of pregnancy vs cyclic zebu multiparous cows.

The roles of glycine and alanine in FF are also equivocal. They have both been found to be higher in FF of lactating cows, which tend to present impaired fertility (Forde et al. 2016b), while other reports link higher glycine and alanine concentrations with oocytes that produce better embryos (Matoba et al. 2014). These differences may be a result of the effect of synchrony, follicle type, postmortem alterations, or a combination of those.

Forde et al. (2016b) reported that methionine concentration in FF of dairy cattle was negatively correlated with beta-hydroxybutyrate (a compound associated with negative energy balance and a detrimental effect on reproduction (Ospina et al. 2010)) in blood. Moreover, Sartori et al. (2010) hypothesised that methionine concentration in FF was relevant in fertility differences between cyclic heifers and dry cows compared to lactating animals, and this was confirmed by Forde et al. (2016b). As of UF, methionine presented a clear peak on day 5 compared with day 3 and day 7 in non-lactating, cyclic dairy cows (Tribulo et al. 2019). Methionine was also in a considerably higher concentration in pregnant compared to open beef heifers (13 times) and in highly fertile compared to subfertile beef heifers (18 times) at day 17 (Moraes et al. 2020a). Interestingly, methionine supplementation in feed was found to enhance embryo development by reducing methylation and increasing endogenous lipid reserves (Acosta et al. 2016).

Lipids Lipids fulfil multiple roles in reproductive processes (reviewed by Ribeiro et al. 2016b), and their characterisation presents specific difficulties compared to other metabolite groups. Nomenclature has improved in recent years due to initiatives such as Lipid Maps (Fahy et al. 2009), but technical limitations are still pervasive.

One such factor is that, due to the nature of untargeted metabolomics, only a fraction of the peaks detected can 
be successfully identified. Many of those unidentified peaks are likely to correspond to lipids (Tribulo et al. 2019).

Arachidonic acid and eicosanoidsArachidonic acid is the precursor of a substantial number of biologically important molecules, including eicosanoids such as prostaglandins (Needleman et al. 1986).

The arachidonic acid content in FF was positively correlated to blood concentrations of glucose, insulin and insulin-like growth factor 1 (IGF1), and negatively correlated to beta-hydroxybutyrate at day 19 of pregnancy (Forde et al. 2016b). In the same study, arachidonic acid was also significantly higher in pregnant heifers and dry cows compared to lactating. Both findings indicate that arachidonic acid abundance in FF is related to a good metabolic status and might be an essential factor explaining differences in fertility linked to metabolic stress.

In UF, arachidonic acid was also more abundant in day 15 of oestrus compared to day 15 of pregnancy, likely due to a metabolic conversion to prostaglandins and other derivatives by the embryo (Forde et al. 2017). Similar findings by Simintiras et al. (2019b) support this model.

Prostaglandins, notably F2 alpha and E2, are central to different physiological processes of reproduction (Poyser 1995). UF from pregnant heifers had overall higher concentrations of PGF2a, and among those pregnant, highly fertile ones tended to have higher concentrations than sub-fertile heifers (Moraes et al. 2020b). The authors hypothesised that, since PGF2a is known to modulate endometrial gene expression (Spencer et al. 2013), related signalling pathways are important in explaining fertility differences among the two groups. Simintiras et al. (2019b) did not detect any prostaglandin in UF, possibly because of insufficient analytical sensitivity.

Ribeiro et al. (2016a) described distinct PGF2a profiles in UF of day 15 pregnant cows carrying an ovoid or filamentous embryo, over twice as high as the concentrations found for cyclic cows or pregnancies with tubular embryos at the same timepoint. These differences could be explained by either dissimilar rates of PGF2a production by the embryo across stages, of endometrial transportation or intake, or others. Some evidence also points at toxic effects of PGF2a on the oocyte (Soto et al. 2003) and embryo (Fazio et al. 1997). This is potentially related to pro-inflammatory effects (Poyser 1995) or complex temporal patterns of regulation mediated by polyunsaturated fatty acids (Caldari-Torres et al. 2006). Roles of fatty acids on reproductive physiology are discussed subsequently.

Fatty acidsFindings in correlations between fatty acid abundance to reproductive success are complex to integrate but point in a similar direction. Lower concentrations of (omega-3) polyunsaturated fatty acids, particularly alpha-linolenic acid (ALA) and docosahexanoic acid (DHA), were found in FF of lactating cows (of well-known reduced fertility (Forde et al. 2017)) compared to heifers and non-lactating cows (Forde et al. 2016b). Docosahexaenoic acid was also in lower concentration in FF of lactating cows compared heifers by Bender et al. (2010). Supplementation of physiological concentrations $(1 \mu \mathrm{M})$ of DHA improved bovine oocyte quality in vitro, possibly by aiding cytoplasm maturation of oocytes (Oseikria et al. 2016). Alpha-linolenic acid is vital for oocyte maturation through the MAPK pathway as well as through PGE2 synthesis, and its supplementation improved in vitro maturation of oocytes resulting from cumulus-oocyte complexes (Marei et al. 2009). Similarly, Matoba et al. (2014) found that the probability of oocytes to produce embryos that reach blastocyst stage was positively correlated to ALA concentration in FF and negatively correlated to the concentration of total saturated fatty acids, especially palmitic acid.

Palmitic and stearic acids are major components of the bovine FF (Leroy et al. 2005, Bender et al. 2010) and have been reported to be negatively associated with embryo quality (Leroy et al. 2005). Both palmitic and stearic acid have also been shown to induce apoptosis in human granulosa cells in vitro by affecting acyl-coA metabolism, and arachidonic acid supplementation countered these detrimental effects (Mu et al. 2001).

PhospholipidsPhospholipid profiles varied considerably in endometrium but not in oviduct tissue at days 4 and 7 of oestrus in a study by Belaz et al. (2016), suggested to depend on follicle size and endocrine conditions. Sponchiado et al. (2019) showed that exposure to a day 7 embryo caused a general decrease in concentration of phospholipids in UF, which they attribute to increased cell membrane synthesis.

Moraes et al. (2020b) found that several phosphatidylcholines (typical components of cell membranes) were significantly more abundant in the pregnant uterine lumen at day 17 , potentially due to the secretion of EV by the elongating conceptus. Polyunsaturated phosphatidylcholine appears to significantly attenuate the damaging, pro-inflammatory effects of LPS injection on murine organs (Jung et al. 2013) and might fulfil similar protective functions in the bovine UF.

Other metabolites Glucose is an indispensable nutrient for pre-implantation in cow, at least from the blastocyst stage (Krisher \& Prather 2012). Simintiras et al. (2019C) found an increase of UF glucose at day 14 of oestrus caused by progesterone supplementation, and stronger increasing trends in the concentration of mannitol at days 12-14, also heightened by progesterone. The authors propose that elevated glucose transport towards UF and its conversion to mannitol by aldose reductase are relevant to embryo elongation. Moreover, Moraes et al. (2020b) reported glucose to be signifi- 
cantly more abundant in UF at day 17 of pregnancy compared to oestrus; they make a case for glucose availability and glucose transporters' expression in embryo to be crucial for its development.

Carnitines and derivatives have been found in increased abundance in day 17 UF of pregnant compared to cyclic cows, as well as in highly fertile compared to sub-fertile cows at the same time of pregnancy, likely to fulfil fatty acid transport or antioxidant functions (Moraes et al. 2020a).

In summary, the wealth in metabolomics data amassed so far has increased our understanding of reproduction. However, we suggest that further integration and improvements in analysis tools are needed, especially supporting more sophisticated analytical platforms, such as multidimensional chromatography coupled to mass spectrometry (Stanstrup et al. 2019) and ion mobility spectrometry.

\section{Main themes}

The surveyed body of research studied numerous aspects related to reproductive health and performance though less about immune response even though many proteins identified are immune related. A selection of the articles' findings is discussed here mainly according to their direct relevance to fertility, and secondly to how their findings aid towards biomarker discovery.

Based on the goal, type of the experiment and the phenomenon studied, we grouped most of them into the themes of biomarkers for fertility, hormones and differences between cyclic and pregnant cows.

Some articles were relevant to more than one theme and are therefore discussed more than once. Other studies provided limited value in terms of reliable biochemical information (especially the earliest articles) and were not discussed in the text.

\section{Potential biomarker candidates of fertility}

The word 'biomarker' is used liberally in molecular biology research and the same is apparent in this selection of studies. Differentially expressed proteins or other molecules should be initially reported as potential biomarker candidates. To qualify as a proper biomarker, the molecule or set of molecules needs first be validated in greater numbers and in different sets of samples and by using various methodologies and parameters (e.g. ELISA, Western blot, MRM) (Martins-de-Souza 2010).

Having made that important distinction, the studies in this section report compounds (or molecular features) proposed to affect fertility directly. Articles in Sections 2.4.2 and 2.4.3 typically share the technical approach with these, however their biological question is related to reproductive function in a more indirect fashion.
Molecular imaging technology over a tissue section is a novel technology applied to biomarker discovery. Goncalves et al. (2016) evaluated embryo development stage by mass spectrometry imaging, showing that metabolic fingerprinting was powerful enough to allow discrimination of five developmental stages: oocytes, 2-, 4-, and 8-cell embryos, and blastocysts. By further tandem mass spectrometry (MS/MS) of selected features, seven molecules of different chemical groups were suggested as potential biomarker candidates, most notably phospholipids.

The same group analysed the metabolite composition of FF to determine differences between animals of different reproductive potential (Guerreiro et al. 2018). They developed a seven-compound model that accurately classified non-lactating Bos indicus in three fertility groups according to the number of oocytes they produced (Fert+, control and Fert-). This classification is based on evidence that a higher number of oocytes can be an important factor for fertility in the production of embryos in vitro (Pontes et al. 2011). Some clear trends emerged from the compounds used for prediction: the FF of animals producing few oocytes presented augmented inflammatory compounds, whereas FF of cows producing a higher number of oocytes showed increased phenolic and flavonoid metabolites (notably resveratrol and derivatives), compounds with wellknown antioxidant properties (Mikulski \& Molski 2010). The authors discuss the implications on the reproductive function of these compounds in the pasture the animals were fed, although the intricacies of the interplay between inflammatory and antioxidant processes remain undescribed (Guerreiro et al. 2018).

One research group performed methodologically complementary experiments examining the early embryo proteome. Taken together, the two works (Deutsch et al. 2014, Demant et al. 2015) described proteome signatures encompassing the whole range of oocyte to blastocyst. Specifically, Deutsch et al. (2014) studied oocytes, zygotes, 2- and 4-cell embryos, finding 87 differentially abundant proteins between the four stages; a panel of five selected proteins allowed discrimination. In turn, Demant et al. (2015) reported a sizable increase in abundance of proteins ( $73 \%$ of the total) from day 5 morulae to day 7 blastocyst stages. Interestingly, in agreement with the conclusions of Talbot et al. (2010), the authors emphasised the importance of several annexins in the transition from morula to blastocyst. Worthy of note is that each study carried out validation by an independent technique, either saturation 2-DIGE or SRM (selected reaction monitoring using mass spectrometry, discussed previously), strengthening the reliability of their results. A further necessary step would be to test the predicting value of their potential biomarker candidates on an independent dataset. 


\section{Effect of hormonal differences}

A nexus between metabolism and reproduction is hormonal regulation; the full significance of this interplay and all its components are yet to be understood, although an indisputable main actor is progesterone (Diskin \& Morris 2008). The effect of differences in progesterone levels on the proteome and metabolome of reproductive tissues was evident in all the studies surveyed, both naturally occurring and the following supplementation. Simintiras et al. $(2019 a, b, c)$ found supplementation with progesterone from day 3 of oestrus caused clear changes in metabolites of all classes examined at days 12, 13 and 14 of oestrus cycle in crossbred beef heifers (lipids, amino acids, carbohydrates, peptides, energy substrates, xenobiotics, nucleotides, vitamins and co-factors).

Changes in FF composition throughout oestrus were studied in a foundational study by Wise (1987). He measured ionic, hormonal and enzymatic parameters in both large and small follicles from 152 heifers, reporting reduced enzymatic activity, as well as decreased $\mathrm{Ca}$ and increased $\mathrm{Mg}$ concentrations in larger follicles. Similar results for enzymatic activity were described by Aller et al. (2013). Orsi et al. (2005) reported an effect of day of oestrus cycle on both the abundance of energy substrates (pyruvate, lactate and glucose) and most amino acids. They also compared the composition of FF with that of oocyte maturation medium, suggesting that the sizable difference in pyruvate to lactate ratio may be an indicator of further differences on oocyte metabolism.

Lamy et al. $(2016 a, b)$ found clear fluctuations in proteins, steroid hormones and metabolites in OF throughout the oestrus cycle, whereas in FF differences were less pronounced (Orsi et al. 2005).

A better understanding of the interactions between molecules (proteins and metabolites) in the reproductive tract will lead to deeper insight on the needs of the embryo. This will aid in the improvement of in vitro embryo production and embryo selection for transfer.

We anticipate effective diagnostic and prognostic applications of biomarkers (and perhaps complementary to blood-based) within the reproductive tract following the rapid progress of research in this area.

\section{Differences between pregnancy and cyclic status}

The composition of UF is regulated by both endocrine mechanisms independent of the presence of an embryo (Forde et al. 2014a, Tribulo et al. 2019), and the paracrine influence of an embryo (Sponchiado et al. 2017). A first stage of embryo-maternal communication in uterus has been shown to commence at least as early as day 7 after conception (Sponchiado et al. 2017), while a second stage is triggered by interferon tau signalling at around day 14 of pregnancy (Robinson et al. 2006).

Forde et al. (2011) and Passaro et al. (2016) found no differences between cyclic and pregnant UF in day
7 proteome, and in days 5, 7 and 13 transcriptome, respectively. Sponchiado et al. (2017), however, showed distinct endometrial expression changes induced by pregnancy in the utero-tubal junction and the anterior area, but not in the posterior area of the endometrium, all at day 7. Thus, it is likely that sensitivity limitations of sampling techniques and analytical equipment have prevented many studies from characterising very localised and potentially weaker molecular changes caused by the early embryo in the first week of pregnancy (Gomez \& Munoz 2015). The same study also suggests that a substantial part the embryo's paracrine effect is likely mediated primarily by post-translational modifications of proteins and micro RNA exchanges through exosomes and EVs, as these are more dynamic and versatile mechanisms compared to de novo synthesis of mRNA. In support of a multifactor model for embryomaternal interaction, Nakamura et al. (2020) showed that EVs isolated from day 17 pregnant uterus induced a pro-inflammatory response in endometrium cell culture independent of IFNT; this is hypothesised to regulate uterine receptivity to facilitate conceptus implantation.

Deutsch et al. (2019) integrated proteomics data from six studies through a GO (Gene Ontology) metaanalysis, identifying several significant process clusters in the pre-implantation period of pregnancy, namely 'MHC class II antigen presentation', 'degradation of the extracellular matrix', 'platelet degranulation', 'activation of chaperones by IRE1alpha' and 'glycosphingolipid metabolism'. Each of those clusters contains both upand downregulated proteins, with limited overlap across studies (cathelicidins, legumain, aldose reductase, and TIMP2). The absence of clear-cut trends complicates shortlisting molecules with high biomarker potential for reproductive success.

\section{Endometritis}

Endometritis is an infection of the uterine endometrium with a serious negative effect on cow health and fertility (McDougall 2001). The molecular characterisation of local response to infection in reproductive tissues provides an extreme example of detrimental conditions for fertility to which milder conditions might be related to. Four studies investigating clinical (Choe et al. 2010, Zhang et al. 2017) and subclinical (Ledgard et al. 2015, Helfrich et al. 2020) endometritis have been surveyed in this systematic review. Conjunctly, they highlight the importance of inflammation-related proteins, especially acute phase proteins; among those are heat shock proteins (HSP) and Major Histocompatibility Complex 1 (MHC1) (Choe et al. 2010) as well as cathelicidins, of antimicrobial function (Kosciuczuk et al. 2012). Zhang et al. (2017) found five (cathelicidins 2, 3, 5-7) to be significantly more abundant in endometritic tissue. Ledgard et al. (2015) found cathelicidins highly correlated with the percentage of polymorphonuclear 
leukocytes in UF affected by subclinical endometritis, indicating their production by these immune cells.

Several cytokines are intimately involved in the aetiology of endometritis. Notably, Helfrich et al. (2020) found that pro-inflammatory interleukins $1 \mathrm{~B}, 8$ and $17 \mathrm{~A}$ in UF are potential biomarkers of cytological endometritis. Conversely, Choe et al. (2010) found another proinflammatory interleukin (IL2) only in healthy endometrial tissue. Transcription of IL10, an anti-inflammatory cytokine (Siewe et al. 2006), was upregulated in subclinical endometritic tissue Helfrich et al. (2020) but no changes were detected at the protein level. On the contrary, the protein was found in higher abundance in clinically endometritic UF by Kim et al. (2014). These discrepancies might be related to the degree of pathology or by post-transcriptional regulation.

Ledgard et al. (2015) found several serine protease inhibitors (SERPINB1,3,4) upregulated in UF during subclinical endometritis and speculated about their role in regulating immune homeostasis and inflammation. SERPINA10 was upregulated in endometrium with endometritis, possibly with a similar role as the above (Zhang et al. 2017). Both works also describe an upregulation of annexins, most notably ANXA1 and ANXA2, potentially modulating inflammation through inhibition of PGF2a synthesis or several proinflammatory enzymes (Hutchinson et al. 2011).

S100 proteins have also been characterised related to endometritis. S100A9 was also increased in endometritic UF according to Ledgard et al. (2015) but Helfrich et al. (2020) found no difference in the transcript levels of this protein in endometrium of healthy and diseased animals. This might be associated to regulatory mechanisms posterior to transcription and caused by differences in number of days post-partum or genetic differences between the animal models used. Another protein of potent microbial activity, S100A12, was significantly more abundant in inflamed endometrium (Zhang et al. 2017). These protein families are further discussed in Section 3.3.1.

Immunoglobulins (Ig) are another important protein family related to immune processes, with proven protective roles against pathogens reviewed by Dhaliwal et al. (2001). IgG1 was found to be one of the 20 most abundant proteins in pregnant UF (Forde et al. 2014a). Alavi-Shoushtari et al. (2006) measured several of these proteins in UF in a targeted approach. They highlighted an increase of IgA1 in the follicular phase in agreement with the enhanced uterus defence during that phase compared to the luteal phase. Surprisingly, Zhang et al. (2017) described a decrease in the abundance of several immunoglobulins (IgA1, IgV3-6, IgG4) in diseased compared to healthy endometrial tissue. This could be related to an increased transport from endometrium to UF (Dhaliwal et al. 2001).

In summary, this section discussed several molecular processes underpinning the inflammation and altered immune response resulting from clinical and subclinical endometritis. Some of those mechanisms resemble those underlying reproductive failure in physiologically normal animals. Thus, they are worth researching further to better understand pregnancy failures without a clear aetiology.

\section{Further research}

The interplay between endocrine, metabolic and pathological processes necessitates further investigation, especially to elucidate any possible use of diet adjustments to 'tailor' the molecular milieu of the reproductive tract. The remarkable work of Harlow et al. (2018) examining the effect of diet composition on the composition of bovine UF opens a new area to ameliorate fertility problems in cattle and potentially other species. Also, combining this with embryo transfer can help distinguish the effects of oocyte quality (i.e. supplementation across months before pregnancy) from the immediate effect of the maternal reproductive tract (supplementation aroundthe time of pregnancy) on embryo development.

As discussed previously, characterising the early embryo milieu is difficult because a portion of the embryo-maternal interactions is highly localised and thus challenging to measure. Two research models are particularly promising to cope with this: multiple embryo transfer (Gomez \& Munoz 2015) and localised flushing in vivo.

Multiple embryo transfer $(n>20)$ provides a means to amplify early embryo signals and has been shown not to affect the hormonal environment in non-physiological ways (Gomez \& Munoz 2015). Further proof of the feasibility of this model is the work of Maillo et al. (2015) in which an embryo effect on oviductal transcriptome at day 3 after ovulation was detected only when 50 zygotes were transferred to the oviduct 1.5 days earlier; no effect was detected in artificially inseminated animals carrying a single embryo.

On the other hand, using single embryo research models is more biologically reliable, but as mentioned the insufficient technical sensitivity is a major drawback. The answer may lie in combining and refining recent developments: a localised sampling technique based on clamping (Sponchiado et al. 2017, 2019) or transvaginal endoscopy (Papp et al. 2019) with a tool such as Merocel sponges (Helfrich et al. 2020) to be applied in vivo, thus preventing post mortem-induced alterations. To the authors' knowledge, these techniques have not been applied conjunctly to date but present enormous potential.

Antioxidant supplementation in feed is an attractive possibility, though results have been inconsistent (reviewed by Hansen 2010), highlighting the need for a deeper understanding of the interplay between oxidative status and reproduction, especially within the reproductive tract. Some promising results in mice and bovine embryos produced in vitro have been obtained 
by use of flavonoids and anthocyanins (reviewed by Hansen 2010), or N-acetyl cysteine, although its effect is inconclusive (Bromfield \& lacovides 2017).

Guerreiro et al. (2018) found several antioxidant molecules in FF of high fertility zebu cows originating from pasture on which the animals fed (Brachiaria spp.). One of those, resveratrol, has been shown to improve in vitro fertilisation outcome (Takeo et al. 2014) and blastocyst development (Salzano et al. 2014) when added to oocyte maturation medium. It is unclear what underlies the differences in ingestion or absorption of these compounds and how it relates to the animals' reproductive capacity. However, feed supplementation of resveratrol-containing waste materials or by-products such as grape skin (Pascual-Marti et al. 2001) is an interesting possibility to explore.

As an additional consideration, systemic research at the levels of plasma and reproductive tract as surveyed in the present review represent a step in the right direction. However, this has not fully delivered, to a degree because of difficulties inherent to plasma (especially dominance of a few proteins (Faulkner et al. 2011)). To achieve a deeper understanding of molecular aspects of fertility at the systemic level, two papers are exemplary of approaches to follow: Sun et al. (2015) determined the effect of two types of feed on the metabolome of four different biofluids (rumen, milk, serum and urine), and Moore et al. (2019) studied the influence of the bacterial metagenome of early post-partum bovine endometrium on endometrial transcriptome.

\section{Conclusions}

Cattle reproductive research by proteomics and metabolomics is a relatively young field that has made substantial progress in terms of the volume and quality of the information. Based on the surveyed articles, the link between disease, oxidative stress, inflammation and immune response to short- and long-term fertility has received some coverage but necessitates further molecular research.

On a different note, the need for standards to refer to when comparing pieces of research can be realised by systematising animal management specifications, while improving and implementing techniques for absolute quantification of molecules. Additionally, following guidelines such as REFLECT and ARRIVE will ensure a much higher standard of publication quality with only limited extra effort required.

Two promising research avenues are systemsbiology investigation of the effect of supplementing specific compounds (methionine, resveratrol) on the molecular milieu of the reproductive tract, and the further development of highly localised, in vivo sampling techniques. We envision a breakthrough in the field within the next few years as omics analysis equipment becomes more affordable and widespread, and software tools easier to use. Any further advances may benefit directly the bovine agricultural sector with improvements to fertility, and potentially help alleviate fertility problems in other mammal species.

\section{Supplementary materials}

This is linked to the online version of the paper at https://doi. org/10.1530/REP-20-0047.

\section{Declaration of interest}

The authors declare that there is no conflict of interest that could be perceived as prejudicing the impartiality of the research reported.

\section{Funding}

This work was funded by a partnership (DRCX1302) between New Zealand dairy farmers through DairyNZ Inc. and the Ministry of Business, Innovation, and Employment (MBIE), and by AgResearch Ltd. The funders had no role in study design, data collection and analysis, decision to publish, or preparation of the manuscript.

\section{Author contribution statement}

$\mathrm{N}$ A was responsible for the original manuscript. N A and J L G were responsible for investigation and formal analysis. D K B, J L G and J D M provided supervision and crucial intellectual input into the design, writing and approval of this work.

\section{Acknowledgements}

The authors wish to acknowledge the gracious support of Jenny Juengel by revising the draft, providing valuable comments and criticism. They also wish to thank Claudine Pausma for the artwork.

\section{References}

Acosta DAV, Denicol AC, Tribulo P, Rivelli MI, Skenandore C, Zhou Z, Luchini D, Correa MN, Hansen PJ \& Cardoso FC 2016 Effects of rumen-protected methionine and choline supplementation on the preimplantation embryo in Holstein cows. Theriogenology 85 1669-1679. (https://doi.org/10.1016/j.theriogenology.2016.01.024)

Alavi-Shoushtari SM, Asri-Rezai S \& Abshenas J 2006 A study of the uterine protein variations during the estrus cycle in the cow: a comparison with the serum proteins. Animal Reproduction Science 96 10-20. (https://doi. org/10.1016/j.anireprosci.2005.10.012)

Aller JF, Callejas SS \& Alberio RH 2013 Biochemical and steroid concentrations in follicular fluid and blood plasma in different follicular waves of the estrous cycle from normal and superovulated beef cows. Animal Reproduction Science 142 113-120. (https://doi.org/10.1016/j. anireprosci.2013.09.009)

Almiñana C, Corbin E, Tsikis G, Alcântara-Neto AS, Labas V, Reynaud K, Galio L, Uzbekov R, Garanina AS, Druart X et al. 2017 Oviduct extracellular vesicles protein content and their role during oviduct- 
embryo cross-talk. Reproduction 154 153-168. (https://doi.org/10.1530/ REP-17-0054)

Almiñana C, Tsikis G, Labas V, Uzbekov R, da Silveira JC, Bauersachs S \& Mermillod P 2018 Deciphering the oviductal extracellular vesicles content across the estrous cycle: implications for the gametes-oviduct interactions and the environment of the potential embryo. BMC Genomics 19 622. (https://doi.org/10.1186/s12864-018-4982-5)

Ametaj BN 2017 Demystifying the Myths: Switching Paradigms from Reductionism to Systems Veterinary in Approaching Transition Dairy Cow Diseases, Periparturient Diseases of Dairy Cows, pp. 9-29. Springer. (https://doi.org/10.1007/978-3-319-43033-1_2)

Annes K, Müller DB, Vilela JAP, Valente RS, Caetano DP, Cibin FWS, Milazzotto MP, Mesquita FS, Belaz KRA, Eberlin MN et al. 2019 Influence of follicle size on bovine oocyte lipid composition, follicular metabolic and stress markers, embryo development and blastocyst lipid content. Reproduction, Fertility, and Development 31 462-472. (https:// doi.org/10.1071/RD18109)

Arnold GJ \& Frohlich T 2011 Dynamic proteome signatures in gametes, embryos and their maternal environment. Reproduction, Fertility, and Development 23 81-93. (https://doi.org/10.1071/RD10223)

Artus J, Hue I \& Acloque H 2020 Preimplantation development in ungulates: a 'ménage à quatre' scenario. Reproduction 159 R151-R172. (https://doi.org/10.1530/REP-19-0348)

Ashburner M, Ball CA, Blake JA, Botstein D, Butler H, Cherry JM, Davis AP, Dolinski K, Dwight SS, Eppig JT et al. 2000 Gene ontology: tool for the unification of biology. The Gene Ontology Consortium. Nature Genetics 25 25-29. (https://doi.org/10.1038/75556)

Banliat C, Dubuisson F, Corbin E, Beurois J, Tomas D, Le Bourhis D, Salvetti P, Labas V, Mermillod P \& Saint-Dizier M 2019a Intraoviductal concentrations of steroid hormones during in vitro culture changed phospholipid profiles and cryotolerance of bovine embryos. Molecular Reproduction and Development 86 661-672. (https://doi.org/10.1002/ mrd.23144)

Banliat C, Tomas D, Teixeira-Gomes AP, Uzbekova S, Guyonnet B, Labas V \& Saint-Dizier M 2019b Stage-dependent changes in oviductal phospholipid profiles throughout the estrous cycle in cattle. Theriogenology 135 65-72. (https://doi.org/10.1016/j. theriogenology.2019.06.011)

Banliat C, Tsikis G, Labas V, Teixeira-Gomes AP, Com E, Lavigne R, Pineau C, Guyonnet B, Mermillod P \& Saint-Dizier M 2020 Identification of 56 proteins involved in embryo-maternal interactions in the bovine oviduct. International Journal of Molecular Sciences 21 17. (https://doi. org/10.3390/ijms21020466)

Belaz KR, Tata A, França MR, Santos da Silva MI, Vendramini PH, Fernandes AM, D'Alexandri FL, Eberlin MN \& Binelli M 2016 Phospholipid profile and distribution in the receptive oviduct and uterus during early diestrus in cattle. Biology of Reproduction 95 127. (https:// doi.org/10.1095/biolreprod.116.142257)

Beltman ME, Mullen MP, Elia G, Hilliard M, Diskin MG, Evans AC \& Crowe MA 2014 Global proteomic characterization of uterine histotroph recovered from beef heifers yielding good quality and degenerate day 7 embryos. Domestic Animal Endocrinology 46 49-57. (https://doi. org/10.1016/j.domaniend.2013.10.003)

Bender K, Walsh S, Evans AC, Fair T \& Brennan L 2010 Metabolite concentrations in follicular fluid may explain differences in fertility between heifers and lactating cows. Reproduction 139 1047-1055. (https://doi.org/10.1530/REP-10-0068)

Berendt FJ, Frohlich T, Schmidt SE, Reichenbach HD, Wolf E \& Arnold GJ 2005 Holistic differential analysis of embryo-induced alterations in the proteome of bovine endometrium in the preattachment period. Proteomics 5 2551-2560. (https://doi.org/10.1002/pmic.200401242)

Berglund B 2008 Genetic improvement of dairy cow reproductive performance. Reproduction in Domestic Animals 43 (Supplement 2) 89-95. (https://doi.org/10.1111/j.1439-0531.2008.01147.x)

Berkkanoglu M, Isikoglu M, Seleker M \& Ozgur K 2006 Flushing the endometrium prior to the embryo transfer does not affect the pregnancy rate. Reproductive Biomedicine Online 13 268-271. (https://doi. org/10.1016/S1472-6483(10)60625-6)

Besenfelder U, Havlicek V, Mösslacher G \& Brem G 2001 Collection of tubal stage bovine embryos by means of endoscopy a technique report. Theriogenology 55 837-845. (https://doi.org/10.1016/s0093691x(01)00447-2)
Bhagwat SR, Redij T, Phalnikar K, Nayak S, Iyer S, Gadkar S, Chaudhari U, Kholkute SD \& Sachdeva G 2014 Cell surfactomes of two endometrial epithelial cell lines that differ in their adhesiveness to embryonic cells. Molecular Reproduction and Development 81 326-340. (https://doi. org/10.1002/mrd.22301)

Bhojwani M, Rudolph E, Kanitz W, Zuehlke H, Schneider F \& Tomek W 2006 Molecular analysis of maturation processes by protein and phosphoprotein profiling during in vitro maturation of bovine oocytes: a proteomic approach. Cloning and Stem Cells 8 259-274. (https://doi. org/10.1089/clo.2006.8.259)

Bromfield JJ \& lacovides SM 2017 Evaluating lipopolysaccharideinduced oxidative stress in bovine granulosa cells. Journal of Assisted Reproduction and Genetics 34 1619-1626. (https://doi.org/10.1007/ s10815-017-1031-2)

Caldari-Torres C, Rodriguez-Sallaberry C, Greene ES \& Badinga L 2006 Differential effects of $n-3$ and n- 6 fatty acids on prostaglandin F2alpha production by bovine endometrial cells. Journal of Dairy Science 89 971-977. (https://doi.org/10.3168/jds.S0022-0302(06)72162-2)

Carvalho JB, Carvalho NA, Reis EL, Nichi M, Souza AH \& Baruselli PS 2008 Effect of early luteolysis in progesterone-based timed Al protocols in Bos indicus, Bos indicus $x$ Bos taurus, and Bos taurus heifers. Theriogenology 69 167-175. (https://doi.org/10.1016/j. theriogenology.2007.08.035)

Ceciliani F, Vecchio D, De Carlo E, Martucciello A \& Lecchi C 2017 A systems biology approach to dairy cattle subfertility and infertility. In Periparturient Diseases of Dairy Cows, pp. 93-119. Eds BN Ametaj. Cham: Springer International Publishing. (https://doi.org/10.1007/9783-319-43033-1_6)

Ceciliani F, Lecchi C, Urh C \& Sauerwein H 2018 Proteomics and metabolomics characterizing the pathophysiology of adaptive reactions to the metabolic challenges during the transition from late pregnancy to early lactation in dairy cows. Journal of Proteomics 178 92-106. (https:// doi.org/10.1016/j.jprot.2017.10.010)

Cesari A, Monclus Mde L, Tejon GP, Clementi M \& Fornes MW 2010 Regulated serine proteinase lytic system on mammalian sperm surface: there must be a role. Theriogenology 74 699.e1-711.e5. (https://doi. org/10.1016/j.theriogenology.2010.03.029)

Choe C, Park JW, Kim ES, Lee SG, Park SY, Lee JS, Cho MJ, Kang KR, Han J \& Kang D 2010 Proteomic analysis of differentially expressed proteins in bovine endometrium with endometritis. Korean Journal of Physiology and Pharmacology 14 205-212. (https://doi.org/10.4196/ kjpp.2010.14.4.205)

De Maio A 1999 Heat shock proteins: facts, thoughts, and dreams. Shock 11 1-12. (https://doi.org/10.1097/00024382-199901000-00001)

Demant M, Deutsch DR, Frohlich T, Wolf E \& Arnold GJ 2015 Proteome analysis of early lineage specification in bovine embryos. Proteomics 15 688-701. (https://doi.org/10.1002/pmic.201400251)

Destaillats F \& Cruz-Hernandez C 2007 Fast analysis by gas-liquid chromatography. Perspective on the resolution of complex fatty acid compositions. Journal of Chromatography, A 1169 175-178. (https://doi. org/10.1016/j.chroma.2007.08.073)

Deutsch DR, Frohlich T, Otte KA, Beck A, Habermann FA, Wolf E \& Arnold GJ 2014 Stage-specific proteome signatures in early bovine embryo development. Journal of Proteome Research 13 4363-4376. (https://doi.org/10.1021/pr500550t)

Deutsch DR, Fröhlich T \& Arnold GJ 2019 Proteomics of Bovine Endometrium, Oocytes and Early Embryos, Reproduction in Domestic Ruminants VIII. Bioscientifica. (https://doi.org/10.1530/biosciprocs.8.003)

Dhaliwal GS, Murray RD \& Woldehiwet Z 2001 Some aspects of immunology of the bovine uterus related to treatments for endometritis. Animal Reproduction Science 67 135-152. (https://doi.org/10.1016/ S0378-4320(01)00124-5)

Diskin MG \& Morris DG 2008 Embryonic and early foetal losses in cattle and other ruminants. Reproduction in Domestic Animals 43 (Supplement 2) 260-267. (https://doi.org/10.1111/j.1439-0531.2008.01171.x)

Fahy E, Subramaniam S, Murphy RC, Nishijima M, Raetz CR, Shimizu T, Spener F, van Meer G, Wakelam MJ \& Dennis EA 2009 Update of the LIPID MAPS comprehensive classification system for lipids. Journal of Lipid Research 50 (Supplement) S9-S14. (https://doi.org/10.1194/jlr. R800095-JLR200)

Faulkner S, Elia G, Hillard M, O'Boyle P, Dunn M \& Morris D 2011 Immunodepletion of albumin and immunoglobulin $G$ from bovine 
plasma. Proteomics $11 \quad 2329-2335 . \quad$ (https://doi.org/10.1002/ pmic.201000364)

Faulkner S, Elia G, Mullen MP, O'Boyle P, Dunn MJ \& Morris D 2012 A comparison of the bovine uterine and plasma proteome using iTRAQ proteomics. Proteomics 12 2014-2023. (https://doi.org/10.1002/ pmic.201100609)

Faulkner S, Elia G, O' Boyle P, Dunn M \& Morris D 2013 Composition of the bovine uterine proteome is associated with stage of cycle and concentration of systemic progesterone. Proteomics 13 3333-3353. (https://doi.org/10.1002/pmic.201300204)

Fazio R, Buuck M \& Schrick F 1997 Embryonic Development of FrozenThawed Bovine Embryos Cultured In Vitro in Response to Elevated Concentrations of Prostaglandin F-2 Alpha, Biology of Reproduction, pp. 420-420. Madison, WI: SOC Study Reproduction.

Forde N \& Lonergan P 2012 Transcriptomic analysis of the bovine endometrium: what is required to establish uterine receptivity to implantation in cattle? Journal of Reproduction and Development 58 189-195. (https://doi.org/10.1262/jrd.2011-021)

Forde N, Carter F, Spencer TE, Bazer FW, Sandra O, Mansouri-Attia N, Okumu LA, McGettigan PA, Mehta JP, McBride R et al. 2011 Conceptusinduced changes in the endometrial transcriptome: how soon does the cow know she is pregnant? Biology of Reproduction 85 144-156. (https://doi.org/10.1095/biolreprod.110.090019)

Forde N, Mehta JP, McGettigan PA, Mamo S, Bazer FW, Spencer TE \& Lonergan P 2013 Alterations in expression of endometrial genes coding for proteins secreted into the uterine lumen during conceptus elongation in cattle. BMC Genomics 14 321. (https://doi.org/10.1186/1471-216414-321)

Forde N, McGettigan PA, Mehta JP, O'Hara L, Mamo S, Bazer FW, Spencer TE \& Lonergan P 2014a Proteomic analysis of uterine fluid during the pre-implantation period of pregnancy in cattle. Reproduction 147 575-587. (https://doi.org/10.1530/REP-13-0010)

Forde N, Simintiras CA, Sturmey R, Mamo S, Kelly AK, Spencer TE, Bazer FW \& Lonergan P $2014 b$ Amino acids in the uterine luminal fluid reflects the temporal changes in transporter expression in the endometrium and conceptus during early pregnancy in cattle. PLOS ONE 9 e100010. (https://doi.org/10.1371/journal.pone.0100010)

Forde N, Bazer FW, Spencer TE \& Lonergan P 2015 'Conceptualizing' the endometrium: identification of conceptus-derived proteins during early pregnancy in cattle. Biology of Reproduction 92 156. (https://doi. org/10.1095/biolreprod.115.129296)

Forde N, Maillo V, O'Gaora P, Simintiras CA, Sturmey RG, Ealy AD, Spencer TE, Gutierrez-Adan A, Rizos D \& Lonergan P 2016a Sexually dimorphic gene expression in bovine conceptuses at the initiation of implantation. Biology of Reproduction 95 92. (https://doi.org/10.1095/ biolreprod.116.139857)

Forde N, O'Gorman A, Whelan H, Duffy P, O'Hara L, Kelly AK, Havlicek V, Besenfelder U, Brennan L \& Lonergan P 2016 b Lactation-induced changes in metabolic status and follicular-fluid metabolomic profile in postpartum dairy cows. Reproduction, Fertility, and Development 28 1882-1892. (https://doi.org/10.1071/RD14348)

Forde N, Simintiras CA, Sturmey RG, Graf A, Wolf E, Blum H \& Lonergan P 2017 Effect of lactation on conceptus-maternal interactions at the initiation of implantation in cattle: I. Effects on the conceptus transcriptome and amino acid composition of the uterine luminal fluid. Biology of Reproduction 97 798-809. (https://doi.org/10.1093/biolre/ iox135)

Garnsworthy PC, Sinclair KD \& Webb R 2008 Integration of physiological mechanisms that influence fertility in dairy cows. Animal 2 1144-1152. (https://doi.org/10.1017/S1751731108002358)

Gegenfurtner K, Fröhlich T, Flenkenthaler F, Kösters M, Fritz S, Desnoës O, Le Bourhis D, Salvetti P, Sandra O, Charpigny G et al. 2019a Genetic merit for fertility alters the bovine uterine luminal fluid proteome. Biology of Reproduction 102 730-739. (https://doi.org/10.1093/biolre/ioz216)

Gegenfurtner K, Frohlich T, Kosters M, Mermillod P, Locatelli Y, Fritz S, Salvetti P, Forde N, Lonergan P, Wolf E et al. 2019b Influence of metabolic status and genetic merit for fertility on proteomic composition of bovine oviduct fluid. Biology of Reproduction 101 893-905. (https:// doi.org/10.1093/biolre/ioz142)

Giergiel M, Wawrzykowski J \& Kankofer M 2018 Comparison between endometrial protein profile in Holstein-Friesian heifers and female prepubertal calves. Veterinaria Italiana $\mathbf{5 4}$ 211-218. (https://doi. org/10.12834/Vetlt.1002.5292.1)

Gilbert RO 2019 Symposium review: Mechanisms of disruption of fertility by infectious diseases of the reproductive tract. Journal of Dairy Science 102 3754-3765. (https://doi.org/10.3168/jds.2018-15602)

Goldansaz SA, Guo AC, Sajed T, Steele MA, Plastow GS \& Wishart DS 2017 Livestock metabolomics and the livestock metabolome: a systematic review. PLoS ONE 12 e0177675. (https://doi.org/10.1371/ journal.pone.0177675)

Gomez E \& Munoz M 2015 Multiple-embryo transfer for studying very early mwaternal-embryo interactions in cattle. Reproduction $\mathbf{1 5 0}$ R35-R43. (https://doi.org/10.1530/REP-14-0465)

Goncalves RF, Ferreira MS, de Oliveira DN, Canevarolo R, Achilles MA, D'Ercole DL, Bols PE, Visintin JA, Killian GJ \& Catharino RR 2016 Analysis and characterisation of bovine oocyte and embryo biomarkers by matrix-assisted desorption ionisation mass spectrometry imaging. Reproduction, Fertility, and Development 28 293-301. (https://doi. org/10.1071/RD14047)

Gray CA, Burghardt RC, Johnson GA, Bazer FW \& Spencer TE 2002 Evidence that absence of endometrial gland secretions in uterine gland knockout ewes compromises conceptus survival and elongation. Reproduction 124 289-300. (https://doi.org/10.1530/rep.0.1240289)

Groebner AE, Rubio-Aliaga I, Schulke K, Reichenbach HD, Daniel H, Wolf E, Meyer HH \& Ulbrich SE 2011a Increase of essential amino acids in the bovine uterine lumen during preimplantation development. Reproduction 141 685-695. (https://doi.org/10.1530/REP-10-0533))

Groebner AE, Schulke K, Schefold JC, Fusch G, Sinowatz F, Reichenbach HD, Wolf E, Meyer HH \& Ulbrich SE 2011 b Immunological mechanisms to establish embryo tolerance in early bovine pregnancy. Reproduction, Fertility, and Development 23 619-632. (https://doi. org/10.1071/RD10230)

Guerin P, El Mouatassim S \& Menezo Y 2001 Oxidative stress and protection against reactive oxygen species in the pre-implantation embryo and its surroundings. Human Reproduction Update 7 175-189. (https://doi.org/10.1093/humupd/7.2.175)

Guerreiro TM, Goncalves RF, Melo CFOR, de Oliveira DN, Lima EO, Visintin JA, de Achilles MA \& Catharino RR 2018 A metabolomic overview of follicular fluid in cows. Frontiers in Veterinary Science $\mathbf{5} 10$. (https://doi.org/10.3389/fvets.2018.00010)

Guise MB \& Gwazdauskas FC 1987 Profiles of uterine protein in flushings and progesterone in plasma of normal and repeat-breeding dairy cattle. Journal of Dairy Science 70 2635-2641. (https://doi.org/10.3168/jds. S0022-0302(87)80333-8)

Hansen PJ 2010 Supplemental antioxidants to enhance fertility in dairy cattle. In 21st Annual FL Ruminant Nutrition Symposium, pp. 157-166, Gainesville, FL, USA.

Harlow K, Taylor E, Casey T, Hedrick V, Sobreira T, Aryal UK, Lemenager RP, Funnell B \& Stewart K 2018 Diet impacts pre-implantation histotroph proteomes in beef cattle. Journal of Proteome Research 17 2144-2155. (https://doi.org/10.1021/acs.jproteome.8b00077)

Hayes BJ, Bowman PJ, Chamberlain AJ \& Goddard ME 2009 Invited review: Genomic selection in dairy cattle: progress and challenges. Journal of Dairy Science 92 433-443. (https://doi.org/10.3168/jds.20081646)

Helfrich AL, Reichenbach HD, Meyerholz MM, Schoon HA, Arnold GJ, Frohlich T, Weber F \& Zerbe H 2020 Novel sampling procedure to characterize bovine subclinical endometritis by uterine secretions and tissue. Theriogenology 141 186-196. (https://doi.org/10.1016/j. theriogenology.2019.09.016)

Hemmings KE, Leese HJ \& Picton HM 2012 Amino acid turnover by bovine oocytes provides an index of oocyte developmental competence in vitro. Biology of Reproduction 86 165, 1-12. (https://doi.org/10.1095/ biolreprod.111.092585)

Horan B, Mee JF, Rath M, O'Connor PO \& Dillon P 2004 The effect of strain of Holstein-Friesian cow and feeding system on reproductive performance in seasonal-calving milk production systems. Animal Science 79 453-467. (https://doi.org/10.1017/S1357729800090329)

Hugentobler SA, Morris DG, Sreenan JM \& Diskin MG 2007a Ion concentrations in oviduct and uterine fluid and blood serum during the estrous cycle in the bovine. Theriogenology 68 538-548. (https://doi. org/10.1016/j.theriogenology.2007.04.049) 
Hugentobler SA, Diskin MG, Leese HJ, Humpherson PG, Watson T, Sreenan JM \& Morris DG 2007b Amino acids in oviduct and uterine fluid and blood plasma during the estrous cycle in the bovine. Molecular Reproduction and Development 74 445-454. (https://doi.org/10.1002/ mrd.20607)

Hugentobler SA, Humpherson PG, Leese HJ, Sreenan JM \& Morris DG 2008 Energy substrates in bovine oviduct and uterine fluid and blood plasma during the oestrous cycle. Molecular Reproduction and Development 75 496-503. (https://doi.org/10.1002/mrd.20760)

Hugentobler SA, Sreenan JM, Humpherson PG, Leese HJ, Diskin MG \& Morris DG 2010 Effects of changes in the concentration of systemic progesterone on ions, amino acids and energy substrates in cattle oviduct and uterine fluid and blood. Reproduction, Fertility, and Development 22 684-694. (https://doi.org/10.1071/RD09129)

Hullin-Matsuda F, Luquain-Costaz C, Bouvier J \& Delton-Vandenbroucke I 2009 Bis(monoacylglycero)phosphate, a peculiar phospholipid to control the fate of cholesterol: implications in pathology. Prostaglandins, Leukotrienes, and Essential Fatty Acids 81 313-324. (https://doi. org/10.1016/j.plefa.2009.09.006)

Hunter RH, Cicinelli E \& Einer-Jensen N 2007 Peritoneal fluid as an unrecognised vector between female reproductive tissues. Acta Obstetricia et Gynecologica Scandinavica 86 260-265. (https://doi. org/10.1080/00016340601155098)

Hunter RH, Coy P, Gadea J \& Rath D 2011 Considerations of viscosity in the preliminaries to mammalian fertilisation. Journal of Assisted Reproduction and Genetics 28 191-197. (https://doi.org/10.1007/ s10815-010-9531-3)

Hutchinson JL, Rajagopal SP, Sales KJ \& Jabbour HN 2011 Molecular regulators of resolution of inflammation: potential therapeutic targets in the reproductive system. Reproduction 142 15-28. (https://doi. org/10.1530/REP-11-0069)

Jensen PL, Grøndahl ML, Beck HC, Petersen J, Stroebech L, Christensen ST \& Yding Andersen C 2014a Proteomic analysis of bovine blastocoel fluid and blastocyst cells. Systems Biology in Reproductive Medicine $60127-$ 135. (https://doi.org/10.3109/19396368.2014.894152)

Jensen PL, Beck HC, Petersen TS, Stroebech L, Schmidt M, Rasmussen LM \& Hyttel P 2014b Proteomic analysis of the early bovine yolk sac fluid and cells from the day 13 ovoid and elongated preimplantation embryos. Theriogenology 82 657-667. (https://doi.org/10.1016/j. theriogenology.2014.04.028)

Jung YY, Nam Y, Park YS, Lee HS, Hong SA, Kim BK, Park ES, Chung YH \& Jeong JH 2013 Protective effect of phosphatidylcholine on lipopolysaccharide-induced acute inflammation in multiple organ injury. Korean Journal of Physiology and Pharmacology 17 209-216. (https://doi.org/10.4196/kjpp.2013.17.3.209)

Kilkenny C, Browne WJ, Cuthill IC, Emerson M \& Altman DG 2010 Improving bioscience research reporting: the ARRIVE guidelines for reporting animal research. PLoS Biology 8 e1000412. (https://doi. org/10.1371/journal.pbio.1000412)

Kim IH, Kang HG, Jeong JK, Hur TY \& Jung YH 2014 Inflammatory cytokine concentrations in uterine flush and serum samples from dairy cows with clinical or subclinical endometritis. Theriogenology $\mathbf{8 2}$ 427-432. (https://doi.org/10.1016/j.theriogenology.2014.04.022)

Kosciuczuk EM, Lisowski P, Jarczak J, Strzalkowska N, Jozwik A, Horbanczuk J, Krzyzewski J, Zwierzchowski L \& Bagnicka E 2012 Cathelicidins: family of antimicrobial peptides. A review. Molecular Biology Reports 39 10957-10970. (https://doi.org/10.1007/s11033-0121997-x)

Krisher RL \& Prather RS 2012 A role for the Warburg effect in preimplantation embryo development: metabolic modification to support rapid cell proliferation. Molecular Reproduction and Development 79 311-320. (https://doi.org/10.1002/mrd.22037)

Kyle JE, Zhang X, Weitz KK, Monroe ME, Ibrahim YM, Moore RJ, Cha J, Sun X, Lovelace ES, Wagoner J et al. 2016 Uncovering biologically significant lipid isomers with liquid chromatography, ion mobility spectrometry and mass spectrometry. Analyst 141 1649-1659. (https:// doi.org/10.1039/c5an02062j)

Lamy J, Labas V, Harichaux G, Tsikis G, Mermillod P \& Saint-Dizier M 2016a Regulation of the bovine oviductal fluid proteome. Reproduction 152 629-644. (https://doi.org/10.1530/REP-16-0397)

Lamy J, Liere P, Pianos A, Aprahamian F, Mermillod P \& Saint-Dizier M $2016 b$ Steroid hormones in bovine oviductal fluid during the estrous cycle. Theriogenology 86 1409-1420. (https://doi.org/10.1016/j. theriogenology.2016.04.086)

LeBlanc S 2010 Assessing the association of the level of milk production with reproductive performance in dairy cattle. Journal of Reproduction and Development 56 (Supplement) S1-S7. (https://doi.org/10.1262/ jrd.1056s01)

Ledgard AM, Lee RS \& Peterson AJ 2009 Bovine endometrial legumain and TIMP-2 regulation in response to presence of a conceptus. Molecular Reproduction and Development 76 65-74. (https://doi.org/10.1002/ mrd.20931)

Ledgard AM, Berg MC, McMillan WH, Smolenski G \& Peterson AJ 2012 Effect of asynchronous transfer on bovine embryonic development and relationship with early cycle uterine proteome profiles. Reproduction, Fertility, and Development 24 962-972. (https://doi.org/10.1071/ RD11225)

Ledgard AM, Smolenski GA, Henderson H \& Lee RS-F 2015 Influence of pathogenic bacteria species present in the postpartum bovine uterus on proteome profiles. Reproduction, Fertility, and Development 27 395-406. (https://doi.org/10.1071/RD13144)

Leroy JLMR, Vanholder T, Delanghe JR, Opsomer G, Van Soom A, Bols PE \& de Kruif A 2004a Metabolite and ionic composition of follicular fluid from different-sized follicles and their relationship to serum concentrations in dairy cows. Animal Reproduction Science $\mathbf{8 0}$ 201-211. (https://doi.org/10.1016/S0378-4320(03)00173-8)

Leroy JLMR, Vanholder T, Delanghe JR, Opsomer G, Van Soom A, Bols PE, Dewulf J \& de Kruif A 2004b Metabolic changes in follicular fluid of the dominant follicle in high-yielding dairy cows early post partum. Theriogenology 62 1131-1143. (https://doi.org/10.1016/j. theriogenology.2003.12.017)

Leroy JL, Vanholder T, Mateusen B, Christophe A, Opsomer G, de Kruif A, Genicot G \& Van Soom A 2005 Non-esterified fatty acids in follicular fluid of dairy cows and their effect on developmental capacity of bovine oocytes in vitro. Reproduction 130 485-495. (https://doi.org/10.1530/ rep.1.00735)

Li CQ, Han JW, Yao QL, Zou CD, Xu YJ, Zhang CL, Shang DS, Zhou LY, Zou CX, Sun ZG et al. 2013 Subpathway-GM: identification of metabolic subpathways via joint power of interesting genes and metabolites and their topologies within pathways. Nucleic Acids Research 41 e101e101. (https://doi.org/10.1093/nar/gkt161)

Lucy MC 2001 Reproductive loss in high-producing dairy cattle: where will it end? Journal of Dairy Science 84 1277-1293. (https://doi.org/10.3168/ jds.S0022-0302(01)70158-0)

Lukanidin E \& Sleeman JP 2012 Building the niche: the role of the S100 proteins in metastatic growth. Seminars in Cancer Biology 22 216-225. (https://doi.org/10.1016/j.semcancer.2012.02.006)

Maillo V, Gaora PÓ, Forde N, Besenfelder U, Havlicek V, Burns GW, Spencer TE, Gutierrez-Adan A, Lonergan P \& Rizos D 2015 Oviduct-embryo interactions in cattle: two-way traffic or a one-way street? Biology of Reproduction 92 144. (https://doi.org/10.1095/ biolreprod.115.127969)

Maniwa J, Izumi S, Isobe N \& Terada T 2005 Studies on substantially increased proteins in follicular fluid of bovine ovarian follicular cysts using 2-D PAGE and MALDI-TOF MS. Reproductive Biology and Endocrinology 3 23. (https://doi.org/10.1186/1477-7827-3-23)

Marei WF, Wathes DC \& Fouladi-Nashta AA 2009 The effect of linolenic acid on bovine oocyte maturation and development. Biology of Reproduction 81 1064-1072. (https://doi.org/10.1095/biolreprod.109.076851)

Martins T, Pugliesi G, Sponchiado M, Gonella-Diaza AM, Ojeda-Rojas OA, Rodriguez FD, Ramos RS, Basso AC \& Binelli M 2018 Perturbations in the uterine luminal fluid composition are detrimental to pregnancy establishment in cattle. Journal of Animal Science and Biotechnology 9 70. (https://doi.org/10.1186/s40104-018-0285-6)

Martins-de-Souza D 2010 Is the word 'biomarker' being properly used by proteomics research in neuroscience? European Archives of Psychiatry and Clinical Neuroscience 260 561-562. (https://doi.org/10.1007/ s00406-010-0105-2)

Massicotte L, Coenen K, Mourot M \& Sirard MA 2006 Maternal housekeeping proteins translated during bovine oocyte maturation and early embryo development. Proteomics 6 3811-3820. (https://doi. org/10.1002/pmic.200500803)

Matoba S, Bender K, Fahey AG, Mamo S, Brennan L, Lonergan P \& Fair T 2014 Predictive value of bovine follicular components as 
markers of oocyte developmental potential. Reproduction, Fertility, and Development 26 337-345. (https://doi.org/10.1071/RD13007)

McDougall S 2001 Effects of periparturient diseases and conditions on the reproductive performance of New Zealand dairy cows. New Zealand Veterinary Journal 49 60-67. (https://doi.org/10.1080/00480169.2001. 36204)

McDougall S, Hussein H, Aberdein D, Buckle K, Roche J, Burke C, Mitchell M \& Meier S 2011 Relationships between cytology, bacteriology and vaginal discharge scores and reproductive performance in dairy cattle. Theriogenology 76 229-240. (https://doi.org/10.1016/j. theriogenology.2010.12.024)

McMillan WH, Cox SF, Donnison MJ, Hagemann LJ \& Peterson AJ 1998 Single and twin conceptus development to day 34 of pregnancy after the transfer of in vitro-produced bovine embryos. Theriogenology 49246. (https://doi.org/10.1016/S0093-691X(98)90599-4)

Memili E, Peddinti D, Shack LA, Nanduri B, McCarthy F, Sagirkaya H \& Burgess SC 2007 Bovine germinal vesicle oocyte and cumulus cell proteomics. Reproduction 133 1107-1120. (https://doi.org/10.1530/ REP-06-0149)

Mikulski D \& Molski M 2010 Quantitative structure-antioxidant activity relationship of trans-resveratrol oligomers, trans-4,4'-dihydroxystilbene dimer, trans-resveratrol-3-O-glucuronide, glucosides: trans-piceid, cis-piceid, trans-astringin and trans-resveratrol-4'-O-beta-Dglucopyranoside. European Journal of Medicinal Chemistry 452366 2380. (https://doi.org/10.1016/j.ejmech.2010.02.016)

Moher D, Liberati A, Tetzlaff J, Altman DG \& PRISMA Group 2009 Preferred reporting items for systematic reviews and meta-analyses: the PRISMA statement. Annals of Internal Medicine 151 264-269, W64. (https://doi.org/10.7326/0003-4819-151-4-200908180-00135)

Mondejar I, Acuna OS, Izquierdo-Rico MJ, Coy P \& Aviles M 2012 The oviduct: functional genomic and proteomic approach. Reproduction in Domestic Animals 47 (Supplement 3) 22-29. (https://doi.org/10.1111/ j.1439-0531.2012.02027.x)

Moore S G, O'Gorman A, Brennan L, Fair T \& Butler S T 2015 Follicular fluid and serum metabolites in Holstein cows are predictive of genetic merit for fertility. Reproduction, Fertility and Development 29 658-669. (https://doi.org/10.1071/RD15182)

Moore SG, Ericsson AC, Behura SK, Lamberson WR, Evans TJ, McCabe MS, Poock SE \& Lucy MC 2019 Concurrent and long-term associations between the endometrial microbiota and endometrial transcriptome in postpartum dairy cows. BMC Genomics 20 405. (https://doi.org/10.1186/ s12864-019-5797-8)

Moraes JGN, Behura SK, Bishop JV, Hansen TR, Geary TW \& Spencer TE 2020a Analysis of the uterine lumen in fertility-classified heifers: II. Proteins and metabolites. Biology of Reproduction 102 571-587. (https://doi.org/10.1093/biolre/ioz197)

Moraes JGN, Behura SK, Geary TW \& Spencer TE 2020b Analysis of the uterine lumen in fertility-classified heifers: I. Glucose, prostaglandins, and lipids. Biology of Reproduction 102 456-474. (https://doi. org/10.1093/biolre/ioz191)

Mu YM, Yanase T, Nishi Y, Tanaka A, Saito M, Jin CH, Mukasa C, Okabe T, Nomura M, Goto K et al. 2001 Saturated FFAs, palmitic acid and stearic acid, induce apoptosis in human granulosa cells. Endocrinology 142 3590-3597. (https://doi.org/10.1210/endo.142.8.8293)

Mullen MP, Elia G, Hilliard M, Parr MH, Diskin MG, Evans AC \& Crowe MA 2012 Proteomic characterization of histotroph during the preimplantation phase of the estrous cycle in cattle. Journal of Proteome Research 11 3004-3018. (https://doi.org/10.1021/pr300144q)

Muñoz M, Corrales FJ, Caamano JN, Diez C, Trigal B, Mora MI, Martin D, Carrocera S \& Gomez E 2012 Proteome of the early embryo-maternal dialogue in the cattle uterus. Journal of Proteome Research 11 751-766. (https://doi.org/10.1021/pr200969a)

Nagana Gowda GA \& Raftery D 2017 Recent advances in NMRbased metabolomics. Analytical Chemistry 89 490-510. (https://doi. org/10.1021/acs.analchem.6b04420)

Nakamura K, Kusama K, Ideta A, Imakawa K \& Hori M 2020 IFNTindependent effects of intrauterine extracellular vesicles (EVs) in cattle. Reproduction 159 503-511. (https://doi.org/10.1530/REP-19-0314)

Needleman P, Turk J, Jakschik BA, Morrison AR \& Lefkowith JB 1986 Arachidonic acid metabolism. Annual Review of Biochemistry 55 69-102. (https://doi.org/10.1146/annurev.bi.55.070186.000441)

O'Connor AM, Sargeant JM, Gardner IA, Dickson JS, Torrence ME \& ID Consensus Meeting Participants: Dewey CE, Evans RB, Gray JT,
Greiner M, Keefe G, Lefebvre SL, Morley PS, Ramirez A, Sischo W, Smith DR, Snedeker K, Sofos J, Ward MP, Wills R 2010 The REFLECT statement: methods and processes of creating reporting guidelines for randomized controlled trials for livestock and food safety. Journal of veterinary internal medicine 24 57-64. (https://doi.org/10.1111/j.18632378.2009.01311.x)

Oenema J, Koskamp GJ \& Galama PJ 2001 Guiding commercial pilot farms to bridge the gap between experimental and commercial dairy farms; the project 'Cows \& Opportunities'. Netherlands Journal of Agricultural Science 49 277-296. (https://doi.org/10.1016/S15735214(01)80011-7)

Orsi NM, Gopichandran N, Leese HJ, Picton HM \& Harris SE 2005 Fluctuations in bovine ovarian follicular fluid composition throughout the oestrous cycle. Reproduction 129 219-228. (https://doi.org/10.1530/ rep.1.00460)

Oseikria M, Elis S, Maillard V, Corbin E \& Uzbekova S 2016 N-3 polyunsaturated fatty acid DHA during IVM affected oocyte developmental competence in cattle. Theriogenology 85 1625.e2-1634. e2. (https://doi.org/10.1016/j.theriogenology.2016.01.019)

Ospina PA, Nydam DV, Stokol T \& Overton TR 2010 Associations of elevated nonesterified fatty acids and beta-hydroxybutyrate concentrations with early lactation reproductive performance and milk production in transition dairy cattle in the northeastern United States. Journal of Dairy Science 93 1596-1603. (https://doi.org/10.3168/jds.2009-2852)

Ott TL 2019 Symposium review: Immunological detection of the bovine conceptus during early pregnancy. Journal of Dairy Science 102 3766-3777. (https://doi.org/10.3168/jds.2018-15668)

Papp SM, Frohlich T, Radefeld K, Havlicek V, Kosters M, Yu H, Mayrhofer C, Brem G, Arnold GJ \& Besenfelder U 2019 A novel approach to study the bovine oviductal fluid proteome using transvaginal endoscopy. Theriogenology 132 53-61. (https://doi.org/10.1016/j. theriogenology.2019.04.009)

Pascual-Marti MC, Salvador A, Chafer A \& Berna A 2001 Supercritical fluid extraction of resveratrol from grape skin of Vitis vinifera and determination by HPLC. Talanta 54 735-740. (https://doi.org/10.1016/ s0039-9140(01)00319-8)

Passaro C, Forde N, Spencer TE \& Lonergan P 201673 proteomic analysis of uterine luminal fluid on day 7 of pregnancy in cattle. Reproduction, Fertility and Development 28 166-166. (https://doi.org/10.1071/ RDv28n2Ab73)

Patti GJ, Yanes O \& Siuzdak G 2012 Innovation: metabolomics: the apogee of the omics trilogy. Nature Reviews: Molecular Cell Biology 13 263-269. (https://doi.org/10.1038/nrm3314)

Philipsson J, Rege J, Zonabend König E \& Okeyo Mwai A 2011 Sustainable Breeding Programmes for Tropical Low- and Medium Input Farming Systems. Nairobi, Kenya: Department of Animal Production, University of Nairobi.

Pillai VV, Weber DM, Phinney BS \& Selvaraj V 2017 Profiling of proteins secreted in the bovine oviduct reveals diverse functions of this luminal microenvironment. PLOS ONE 12 e0188105. (https://doi.org/10.1371/ journal.pone.0188105)

Pinu FR, Beale DJ, Paten AM, Kouremenos K, Swarup S, Schirra HJ \& Wishart D 2019 Systems biology and multi-omics integration: viewpoints from the Metabolomics Research Community. Metabolites 9 76. (https:// doi.org/10.3390/metabo9040076)

Pontes JHF, Melo Sterza FA, Basso AC, Ferreira CR, Sanches BV, Rubin KCP \& Seneda MM 2011 Ovum pick up, in vitro embryo production, and pregnancy rates from a large-scale commercial program using Nelore cattle (Bos indicus) donors. Theriogenology 75 1640-1646. (https://doi. org/10.1016/j.theriogenology.2010.12.026)

Poyser NL 1995 The control of prostaglandin production by the endometrium in relation to luteolysis and menstruation. Prostaglandins, Leukotrienes, and Essential Fatty Acids 53 147-195. (https://doi. org/10.1016/0952-3278(95)90115-9)

Renaville B, Bacciu N, Comin A, Motta M, Poli I, Vanini G \& Prandi A 2010 Plasma and follicular fluid fatty acid profiles in dairy cows. Reproduction in Domestic Animals 45 118-121. (https://doi.org/10.1111/j.14390531.2008.01264.x)

Ribeiro ES, Gomes G, Greco LF, Cerri RLA, Vieira-Neto A, Monteiro PLJ, Lima FS, Bisinotto RS, Thatcher WW \& Santos JEP 2016a Carryover effect of postpartum inflammatory diseases on developmental biology and fertility in lactating dairy cows. Journal of Dairy Science 99 2201-2220. (https://doi.org/10.3168/jds.2015-10337) 
Ribeiro ES, Santos JE \& Thatcher WW $2016 b$ Role of lipids on elongation of the preimplantation conceptus in ruminants. Reproduction 152 R115-R126. (https://doi.org/10.1530/REP-16-0104)

Robinson RS, Fray MD, Wathes DC, Lamming GE \& Mann GE 2006 In vivo expression of interferon tau mRNA by the embryonic trophoblast and uterine concentrations of interferon tau protein during early pregnancy in the cow. Molecular Reproduction and Development 73 470-474. (https://doi.org/10.1002/mrd.20431)

Rodrigues TA, Tuna KM, Alli AA, Tribulo P, Hansen PJ, Koh J \& PaulaLopes FF 2019 Follicular fluid exosomes act on the bovine oocyte to improve oocyte competence to support development and survival to heat shock. Reproduction, Fertility, and Development 31 888-897. (https://doi.org/10.1071/RD18450)

Salzano A, Albero G, Zullo G, Neglia G, Abdel-Wahab A, Bifulco G, Zicarelli L \& Gasparrini B 2014 Effect of resveratrol supplementation during culture on the quality and cryotolerance of bovine in vitro produced embryos. Animal Reproduction Science 151 91-96. (https:// doi.org/10.1016/j.anireprosci.2014.09.018)

Sartori R, Bastos MR \& Wiltbank MC 2010 Factors affecting fertilisation and early embryo quality in single- and superovulated dairy cattle. Reproduction, Fertility, and Development 22 151-158. (https://doi. org/10.1071/RD09221)

Shirasuna K, Matsumoto H, Kobayashi E, Nitta A, Haneda S, Matsui M, Kawashima C, Kida K, Shimizu T \& Miyamoto A 2012 Upregulation of interferon-stimulated genes and interleukin-10 in peripheral blood immune cells during early pregnancy in dairy cows. Journal of Reproduction and Development 58 84-90. (https://doi.org/10.1262/ jrd.11-094k)

Siewe L, Bollati-Fogolin M, Wickenhauser C, Krieg T, Müller W \& Roers A 2006 Interleukin-10 derived from macrophages and/or neutrophils regulates the inflammatory response to LPS but not the response to CpG DNA. European Journal of Immunology 36 3248-3255. (https://doi. org/10.1002/eji.200636012)

Simintiras CA, Sanchez JM, McDonald M \& Lonergan P 2019a The influence of progesterone on bovine uterine fluid energy, nucleotide, vitamin, cofactor, peptide, and xenobiotic composition during the conceptus elongation-initiation window. Scientific Reports 97716. (https://doi.org/10.1038/s41598-019-44040-6)

Simintiras CA, Sanchez JM, McDonald M \& Lonergan P 2019b Progesterone alters the bovine uterine fluid lipidome during the period of elongation. Reproduction 157 399-411. (https://doi.org/10.1530/REP-18-0615)

Simintiras CA, Sánchez JM, McDonald M, Martins T, Binelli M \& Lonergan P 2019C Biochemical characterization of progesterone-induced alterations in bovine uterine fluid amino acid and carbohydrate composition during the conceptus elongation window. Biology of Reproduction 100 672-685. (https://doi.org/10.1093/biolre/ioy234)

Soto P, Natzke RP \& Hansen PJ 2003 Identification of possible mediators of embryonic mortality caused by mastitis: actions of lipopolysaccharide, prostaglandin F2alpha, and the nitric oxide generator, sodium nitroprusside dihydrate, on oocyte maturation and embryonic development in cattle. American Journal of Reproductive Immunology 50 263-272. (https://doi.org/10.1034/j.1600-0897.2003.00085.x)

Spencer TE, Forde N, Dorniak P, Hansen TR, Romero JJ \& Lonergan P 2013 Conceptus-derived prostaglandins regulate gene expression in the endometrium prior to pregnancy recognition in ruminants. Reproduction 146 377-387. (https://doi.org/10.1530/REP-13-0165)

Sponchiado M, Gomes NS, Fontes PK, Martins T, Del Collado M, Pastore AA, Pugliesi G, Nogueira MFG \& Binelli M 2017 Pre-hatching embryo-dependent and -independent programming of endometrial function in cattle. PLOS ONE 12 e0175954. (https://doi.org/10.1371/ journal.pone.0175954)

Sponchiado M, Gonella-Diaza AM, Rocha CC, Turco EGL, Pugliesi G, Leroy JLMR \& Binelli M 2019 The pre-hatching bovine embryo transforms the uterine luminal metabolite composition in vivo. Scientific Reports 9 8354. (https://doi.org/10.1038/s41598-019-44590-9)

Stanstrup J, Broeckling CD, Helmus R, Hoffmann N, Mathe E, Naake T, Nicolotti L, Peters K, Rainer J, Salek RM et al. 2019 The metaRbolomics Toolbox in Bioconductor and beyond. Metabolites 9 200. (https://doi. org/10.3390/metabo9100200)

Sturmey RG, Bermejo-Alvarez P, Gutierrez-Adan A, Rizos D, Leese HJ \& Lonergan P 2010 Amino acid metabolism of bovine blastocysts: a biomarker of sex and viability. Molecular Reproduction and Development 77 285-296. (https://doi.org/10.1002/mrd.21145)
Sun HZ, Wang DM, Wang B, Wang JK, Liu HY, Guan le L \& Liu JX 2015 Metabolomics of four Biofluids from dairy cows: potential biomarkers for milk production and quality. Journal of Proteome Research 14 1287-1298. (https://doi.org/10.1021/pr501305g)

Takeo S, Sato D, Kimura K, Monji Y, Kuwayama T, Kawahara-Miki R \& Iwata H 2014 Resveratrol improves the mitochondrial function and fertilization outcome of bovine oocytes. Journal of Reproduction and Development 60 92-99. (https://doi.org/10.1262/jrd.2013-102)

Talbot NC, Powell AM, Caperna TJ \& Garrett WM 2010 Proteomic analysis of the major cellular proteins of bovine trophectoderm cell lines derived from IVP, parthenogenetic and nuclear transfer embryos: reduced expression of annexins I and II in nuclear transfer-derived cell lines. Animal Reproduction Science 120 187-202. (https://doi.org/10.1016/j. anireprosci.2010.03.009)

The Gene Ontology Consortium 2019 The Gene Ontology Resource: 20 years and still GOing strong. Nucleic Acids Research 47 D330-D338. (https://doi.org/10.1093/nar/gky1055)

Tribulo P, Balzano-Nogueira L, Conesa A, Siqueira LG \& Hansen PJ 2019 Changes in the uterine metabolome of the cow during the first 7 days after estrus. Molecular Reproduction and Development 86 75-87. (https://doi.org/10.1002/mrd.23082)

Ulbrich SE, Meyer SU, Zitta K, Hiendleder S, Sinowatz F, Bauersachs S, Buttner M, Frohlich T, Arnold GJ, Reichenbach HD et al. 2011 Bovine endometrial metallopeptidases MMP14 and MMP2 and the metallopeptidase inhibitor TIMP2 participate in maternal preparation of pregnancy. Molecular and Cellular Endocrinology 332 48-57. (https:// doi.org/10.1016/j.mce.2010.09.009)

Ulbrich SE, Groebner AE \& Bauersachs S 2013 Transcriptional profiling to address molecular determinants of endometrial receptivity - lessons from studies in livestock species. Methods 59 108-115. (https://doi. org/10.1016/j.ymeth.2012.10.013)

Velazquez MA, Parrilla I, Van Soom A, Verberckmoes S, Kues W \& Niemann H 2010 Sampling techniques for oviductal and uterine luminal fluid in cattle. Theriogenology 73 758-767. (https://doi.org/10.1016/j. theriogenology.2009.07.004)

Vilella F, Ramirez LB \& Simon C 2013 Lipidomics as an emerging tool to predict endometrial receptivity. Fertility and Sterility 99 1100-1106. (https://doi.org/10.1016/j.fertnstert.2012.12.026)

Wang X, Burghardt RC, Romero JJ, Hansen TR, Wu G \& Bazer FW 2015 Functional roles of arginine during the peri-implantation period of pregnancy. III. Arginine stimulates proliferation and interferon tau production by ovine trophectoderm cells via nitric oxide and polyamineTSC2-mTOR signaling pathways. Biology of Reproduction 92 75. (https:// doi.org/10.1095/biolreprod.114.125989)

Winder CB, Churchill KJ, Sargeant JM, LeBlanc SJ, O'Connor AM \& Renaud DL 2019 Invited review: Completeness of reporting of experiments: REFLECTing on a year of animal trials in the Journal of Dairy Science. Journal of Dairy Science 102 4759-4771. (https://doi. org/10.3168/jds.2018-15797)

Wise T 1987 Biochemical analysis of bovine follicular fluid: albumin, total protein, lysosomal enzymes, ions, steroids and ascorbic acid content in relation to follicular size, rank, atresia classification and day of estrous cycle. Journal of Animal Science 64 1153-1169. (https://doi. org/10.2527/jas1987.6441153x)

Zachut M, Sood P, Livshitz L, Kra G, Levin Y \& Moallem U 2016 Proteome dataset of pre-ovulatory follicular fluids from less fertile dairy cows. Data in Brief 7 1515-1518. (https://doi.org/10.1016/j. dib.2016.04.051)

Zhang SD, Dong SW, Wang DS, Oguejiofor CF, Fouladi-Nashta AA, Yang ZQ \& Yan ZT 2017 Differential proteomic profiling of endometrium and plasma indicate the importance of hydrolysis in bovine endometritis. Journal of Dairy Science 100 9324-9337. (https://doi.org/10.3168/ jds.2016-12365)

Received 30 January 2020

First decision 9 March 2020

Revised manuscript received 19 June 2020

Accepted 3 August 2020 